\title{
Tesserae on Venus: Evidence of Fluvial Erosion and Characterization of Lineaments
}

\author{
By \\ Sara Khawja \\ A thesis submitted to the Faculty of Graduate and Postdoctoral Affairs in \\ partial fulfillment of the requirements for the degree of \\ Master of Science \\ In \\ Earth Sciences \\ Carleton University \\ Ottawa, Ontario \\ (C)2020 \\ Sara Khawja
}




\begin{abstract}
Tesserae are the stratigraphically oldest and geologically complex regions on Venus. Recent global climate models propose that Venus experienced Earth-like temperatures for most of its history prior to catastrophic global warming. This study tests for fluvial erosion prior to global warming by comparing valley patterns in tesserae with terrestrial stream patterns. Valleys were identified by margins of tesserae partially flooded by younger basaltic plains flows. Recognition of erosion in tesserae is a paradigm shift and has numerous implications. One such implication relates to the interpretation of lineaments sets in tesserae.

Multiple lineament sets are characteristic of tesserae and are typically interpreted as the surface trace of fold crests, faults and grabens. However, the interpretation of erosion allows additional interpretations of lineaments as the exposed edges of sedimentary or volcanic sequences. PCA (Principal Component Analysis) can be applied to curving lineaments to calculate dips for such planar geological units and structures.
\end{abstract}




\section{Acknowledgements}

To start from the beginning, I would like to especially thank my supervisors Dr. Richard Ernst and Dr. Claire Samson for offering me the opportunity to conduct research on Venus. Their careful guidance throughout the years helped me produce numerous abstracts, oral presentations and posters for various conferences. I was very grateful to have the opportunity to present my research at the Lunar and Planetary Science conference in Houston, Texas and receive feedback from many well-known planetary scientists. I thank my supervisors for supporting me financially and emotionally as I moved into a new city and began working on a research topic that was complex and not well understood. Lastly, I am incredibly appreciative for their dedication to helping get through the process of developing a thesis and manuscript.

I would also like to extend my gratitude to everyone involved in helping me tackle the geological complexity of tesserae. I thank Dr. Yvette Kuiper (Colorado School of Mines) for helping me explore the structural geology of rocks on another planet. I would also like to thank Dr. Martha Gilmore (Wesleyan University) for leading the discussion for uncertainties in data and how it would impact our work moving forward. Most importantly, I would like to thank Erin Bethell (fellow Venus graduate student) for her generosity and patience with me at the beginning of my Venus journey and informative discussions regarding Venusian geology.

Lastly, my very sincere gratitude goes out to my parents, siblings and friends for their love and support throughout my journey. I would like to especially dedicate this work to my dad (papu). I whole-heartedly appreciate the amount of patience I received from everyone as well as their keen interest in the work that I have been doing. 


\section{Table of Contents}

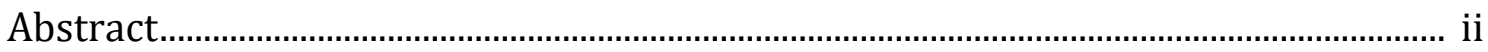

Acknowledgements ............................................................................................................. iii

Table of Contents ………………………………………………………………………... iv

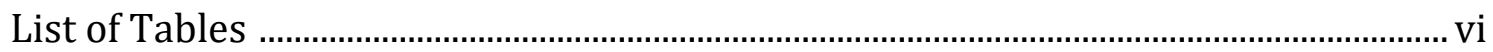

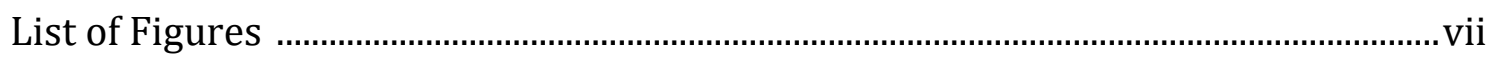

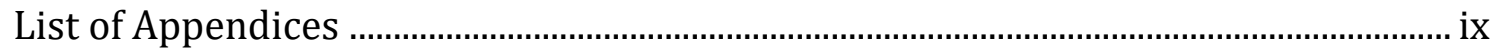

1. Chapter: Introduction ….......................................................................... 1

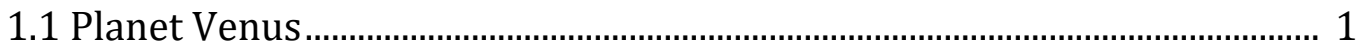

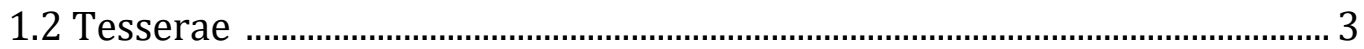

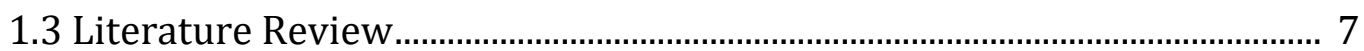

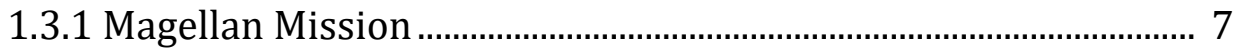

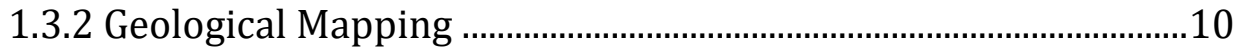

1.3.3 Carleton University Research Group ..............................................11

1.4 Research Objectives and Structure of the Thesis ..........................................12

2. Chapter: Methodology and Study Area ...................................................14

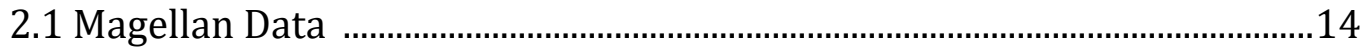

2.2 Mapping and Imaging Software ………………………………………….....16

2.2.1 ArcGIS …………………………………………………………....16

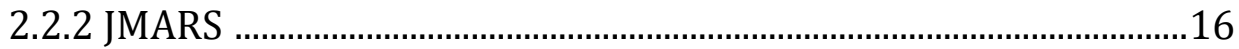

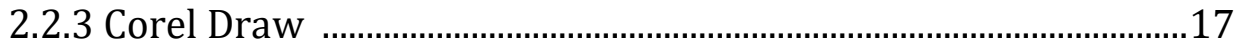

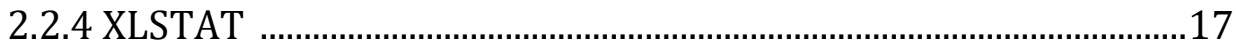

2.3 Study Area …………………………………………………………………. 17

3. Chapter: Fluvial Erosion on Venus …….................................................... 19

3.1 Introduction............................................................................................ 19

3.2 Erosion on Venus ………………………………………………………......19

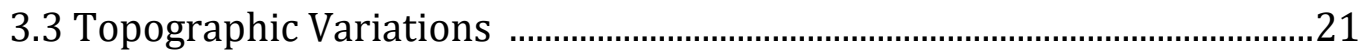

3.4 Methodology for Identifying Topographic Valleys ......................................23

3.5 Primary Topography vs Erosion ....................................................................25

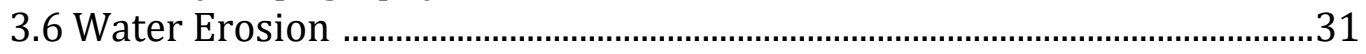

3.6.1 Comparison with Stream Drainage Patterns ................................31

3.6.2 Tear-Drop Shaped Island .................................................................31

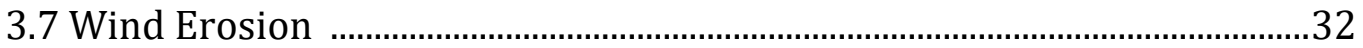

3.8 Glacial Erosion .......................................................................................... 35

3.9 Implications of Fluvial Erosion Interpretation ........................................... 37

3.9.1 Linking Stream Drainage Patterns with Underlying Geology ...38

3.9.2 Simplified Interpretation of Lineament Patterns

in Tesserae 


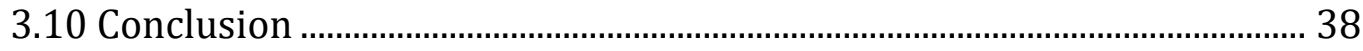

4. Chapter: Influence of Erosion on Tesserae Lineaments ............................... 40

4.1 Introduction..................................................................................................... 40

4.1.1 Lineaments on Tesserae ................................................................. 41

4.1.2 Topographic Profiles ........................................................................4

4.2 Calculating Dip of Planar Surfaces .............................................................. 50

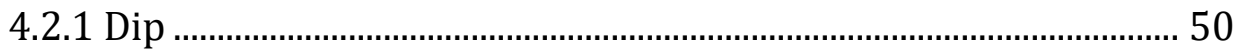

4.2.2 Methodology for Calculating for PCA ………………………….....50

4.2.3 Methodology for Calculating dip .....................................................53

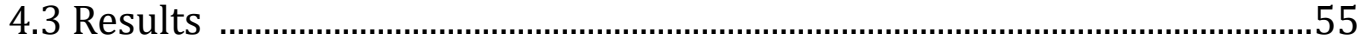

4.3.1 Calculated Examples for Salus Tessera ......................................... 55

4.3.2 Uncertainties Associated with PCA Calculations........................... 57

4.3.3 Role of Erosion .................................................................................. 57

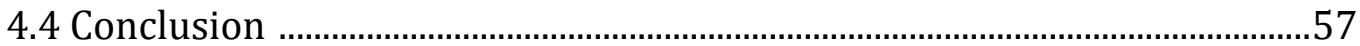

5. Chapter: Summary and Conclusions ............................................................... 59

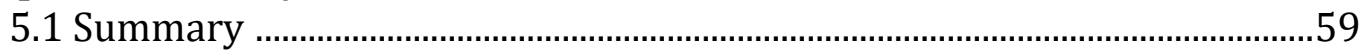

5.2 Fluvial Erosion of Tesserae ………………………………………………. 59

5.3 Interpretation of Lineament Sets in Tesserae............................................. 60

5.4 Recommendations for Future Work ………………………………….... 61

Appendix A: Calculations for Dip and Maximum Angular Deviation

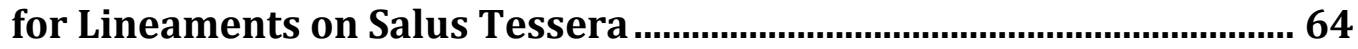

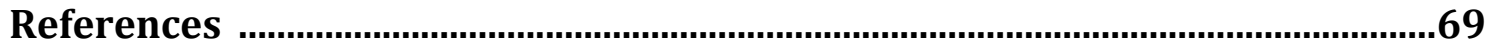




\section{List of Tables}

Table 4.1. Average slope calculated for each topographic profile in Figure 4.2 ...... 44 


\section{List of Figures}

Figure 1.1. Size comparison of Venus and Earth............................................................. 2

Figure 1.2. Global distribution of tesserae on Venus ................................................... 4

Figure 1.3. Global topography of Venus .......................................................................... 5

Figure 1.4. Schematic diagram of Magellan spacecraft ................................................... 9

Figure 1.5. Quadrangles of mapping for Venus .........................................................10

Figure 2.1. Stereo-derived topography overlying Magellan SAR imagery.................. 15

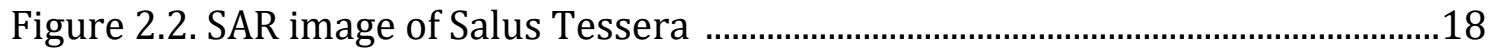

Figure 3.1. Topographic profile of Tellus Regio ...................................................................22

Figure 3.2. Tesserae surrounded by volcanic plains ....................................................24

Figure 3.3. Terrestrial analogues of fluvial erosion ..........................................................24

Figure 3.4. Models to explain topographic variations .................................................25

Figure 3.5. Tectonic and erosional interpretation of tesserae surrounded

by plains unit .26

Figure 3.6. Tectonic and erosional interpretation of the southern region

of Salus Tessera. 26

Figure 3.7. Examples of tesserae regions partially flooded by lava flows and their associated stream drainage patterns 29

Figure 3.8. Additional examples of tesserae regions partially flooded by 
lava flows and their associated stream drainage patterns.

Figure 3.9. Tesserae shaped like a tear drop island 32

Figure 3.10. Examples of features created by aeolian erosion on Earth .34

Figure 3.11. Landforms created by glacial erosion on Earth .36

Figure 4.1. Examples of lineaments seen on Tesserae 41

Figure 4.2. Topographic profiles superimposed on SAR images throughout Salus Tessera .44

Figure 4.3. Block diagrams representing different lineaments on tesserae .45

Figure 4.4. Illustration of the Rule of V's

Figure 4.5. Lineament expression due to folding and erosion 48

Figure 4.6. Eigenvectors associated with a best-fit plane 51

Figure 4.7. Methodology for calculating dip and maximum angular deviation for lineaments .54

Figure 4.8. Dip and associated maximum angular deviation for

7 lineaments analyzed on Salus Tessera .56

Figure 4.9. Detailed look at two lineaments associated with

intermediate dipping planes on Salus Tessera 56 


\section{List of Appendices}

Appendix A: Calculation of orientation of planar features associated with curving lineaments on Salus Tessera ... 


\section{Chapter: Introduction}

\subsection{Planet Venus}

Venus is commonly referred to as Earth's sister planet because of the proximity between these two planets in the solar system and their similarities in terms of size (Figure 1.1), mass, density, composition and gravity (Hoffman et al., 1980). However, Earth-based observations and various space missions to Venus, have revealed very different environments on the two bodies. Contrary to Earth, Venus exhibits a lack of plate tectonics, extreme surface temperatures $\left(\sim 450^{\circ} \mathrm{C}\right)$ and a surface atmospheric pressure of $9000 \mathrm{kPa}$ (90 times that of Earth). This is largely due to a thick atmosphere composed of $96 \% \mathrm{CO}_{2}$, lesser quantities of $\mathrm{N}_{2}$ and $\mathrm{H}_{2} \mathrm{~S}$ and lastly a low-lying cloud layer of sulphuric acid droplets (Donahue and Russell, 1997; Chaisson and McMillan, 2010). These gases created a runaway greenhouse effect by trapping nearly all of the Sun`s incoming radiation, in addition to any internal heat dissipated from the planetary interior. Before the Soviet Union began the Venera space missions in the early 1960's, existing knowledge of Venus' surface conditions and topography remained purely speculative. It was not until 1990`s that the most detailed images of Venus were provided by NASA's 1990-1994 Magellan mission, which collected high resolution (75-100 m/pixel) images of $98 \%$ of the planet's surface using Synthetic Aperture Radar (SAR) (Young, 1990; Saunders et al., 1992; Saunders and Pettengill, 1991). 

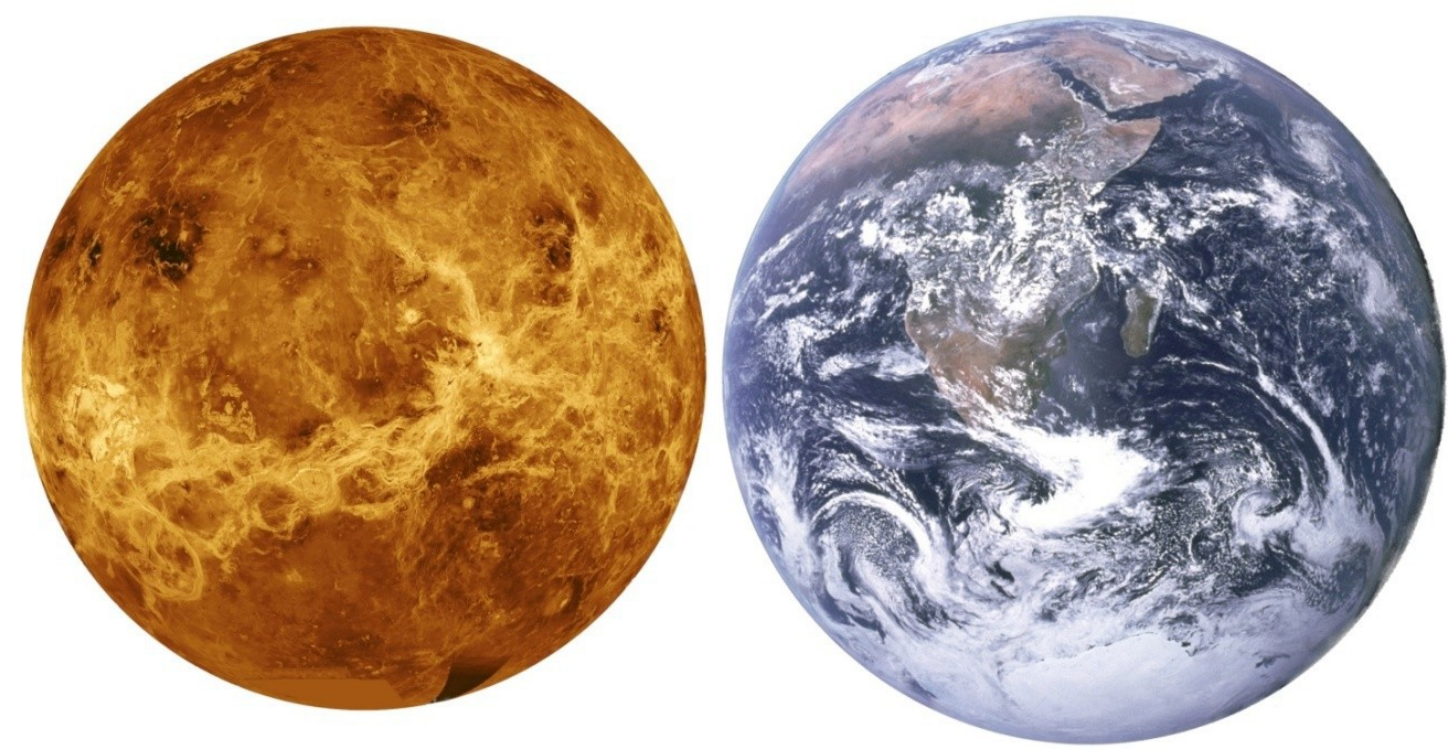

Figure 1.1: Comparison of Venus (shown on left, imaged using microwave spectrum) and Earth (shown on right, imaged using visible spectrum). Source: NASA/JPL.

Venus preserves an extensive history of basaltic intraplate magmatism (e.g. Ernst et al. 2007) consisting of: (1) individual volcanoes that are 100-1000 km in diameter and are interpreted to have a plume origin; (2) annular structures (termed coronae and arachnoids) with diameters averaging $300 \mathrm{~km}$, that can have a diapir or plume origin; (3) radiating graben-fissure systems (including novae) caused by underlying laterally propagating dykes and extending up to 2000-6000 km away from the volcanoes or coronae located at their foci; (4) lava flow fields of scale comparable to terrestrial flood basalts; (5) regions of small shield volcanoes, often a few hundred kilometers across; and (6) canali which are narrow sinuous lava channels whose length can reach up to $7000 \mathrm{~km}$. All these tectono-magmatic features are superimposed on earlier plains' volcanism and highly deformed "basement" terranes termed tesserae. 


\subsection{Tesserae}

Tesserae, also known as complex ridge terrains, occupy approximately $8 \%$ of Venus' surface (Figure 1.2) and are commonly associated with elevated continent-like regions (crustal plateaus) (Figure 1.3) embayed by adjacent volcanic plains (Barsukov et al., 1986; Sukhanov, 1986, 1992; Bindschadler and Head, 1989; Solomon et al., 1992; Bindschadler et al., 1992a,b; Ivanov and Head, 1996a,b; Hansen and Willis, 1996; Pritchard et al., 1997; Head and Basilevsky, 1998 Campbell and Taylor, 2002; Bleamaster and Hansen, 2005; Romeo and Turcotte, 2008; Gilmore and Head, 2018). The age of tesserae has been estimated using the impact crater counting method as $(1.47+/-0.46) \times \mathrm{T}$ where $\mathrm{T}=750 \mathrm{Ma}$ is the average age of the surface of Venus (Ivanov and Basilevsky, 1993; Basilevsky and Head 2002). Tesserae consist of at least two sets of intersecting lineaments (e.g. ridges and grooves) and are the result of tectonic deformation of a precursor terrain (Basilevsky and Head, 1998). The nature of that precursor terrain, as well as the causes and mechanisms of deformation are still under debate (Hansen and Willis, 1996; Gilmore and Head, 2018). Current topics of discussion regarding tesserae are: their extent (global vs regional), and the origin (downwelling vs upwelling) and composition (mafic vs felsic) of their precursor terrains. 


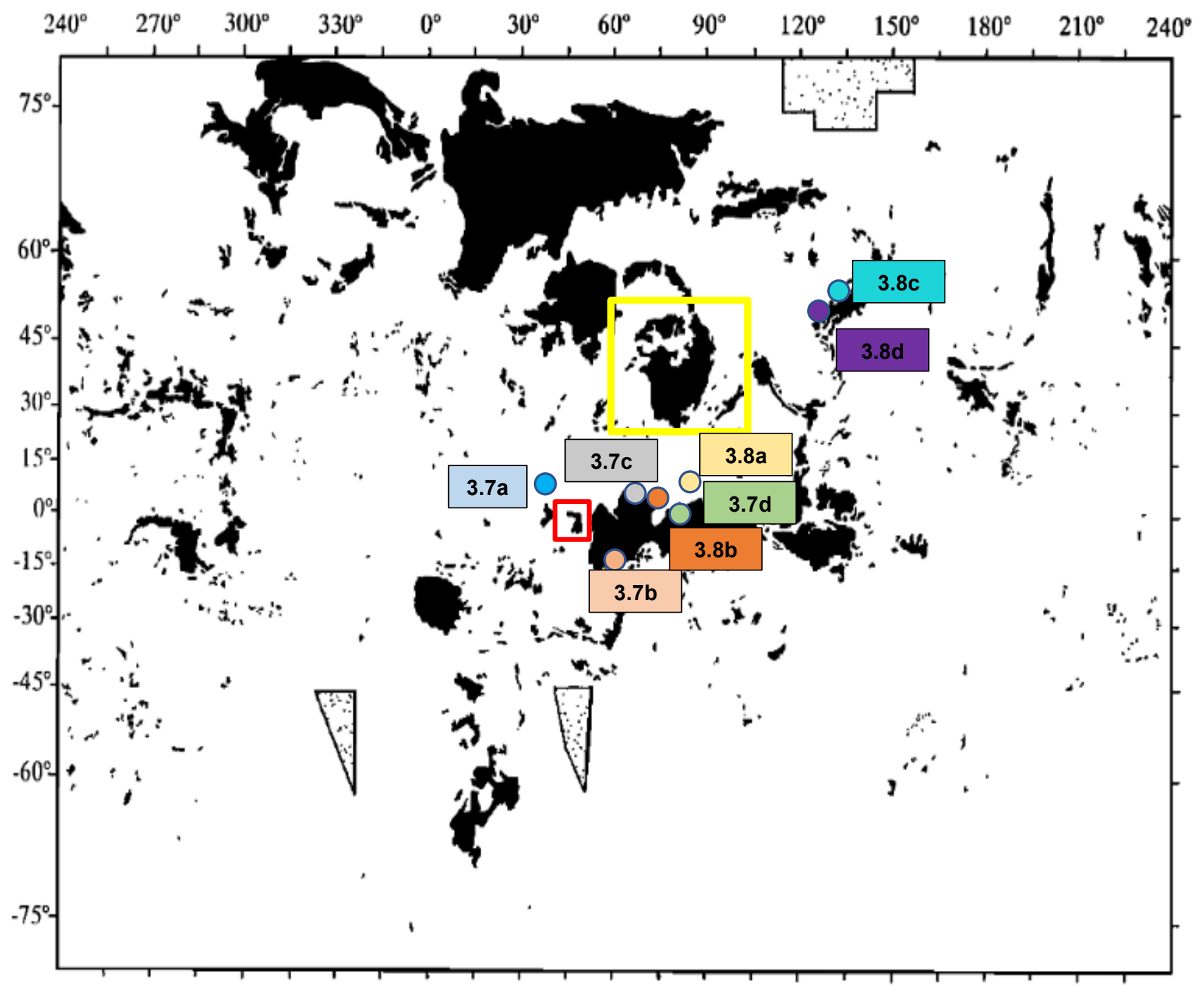

Figure 1.2: Global distribution of tesserae on Venus (Ivanov and Head, 1996). Red box locates Salus Tessera, a key study area in this thesis. Yellow box locates Tellus Regio, discussed in Chapter 3. Location of Figures 3.7 and 3.8 are shown. 


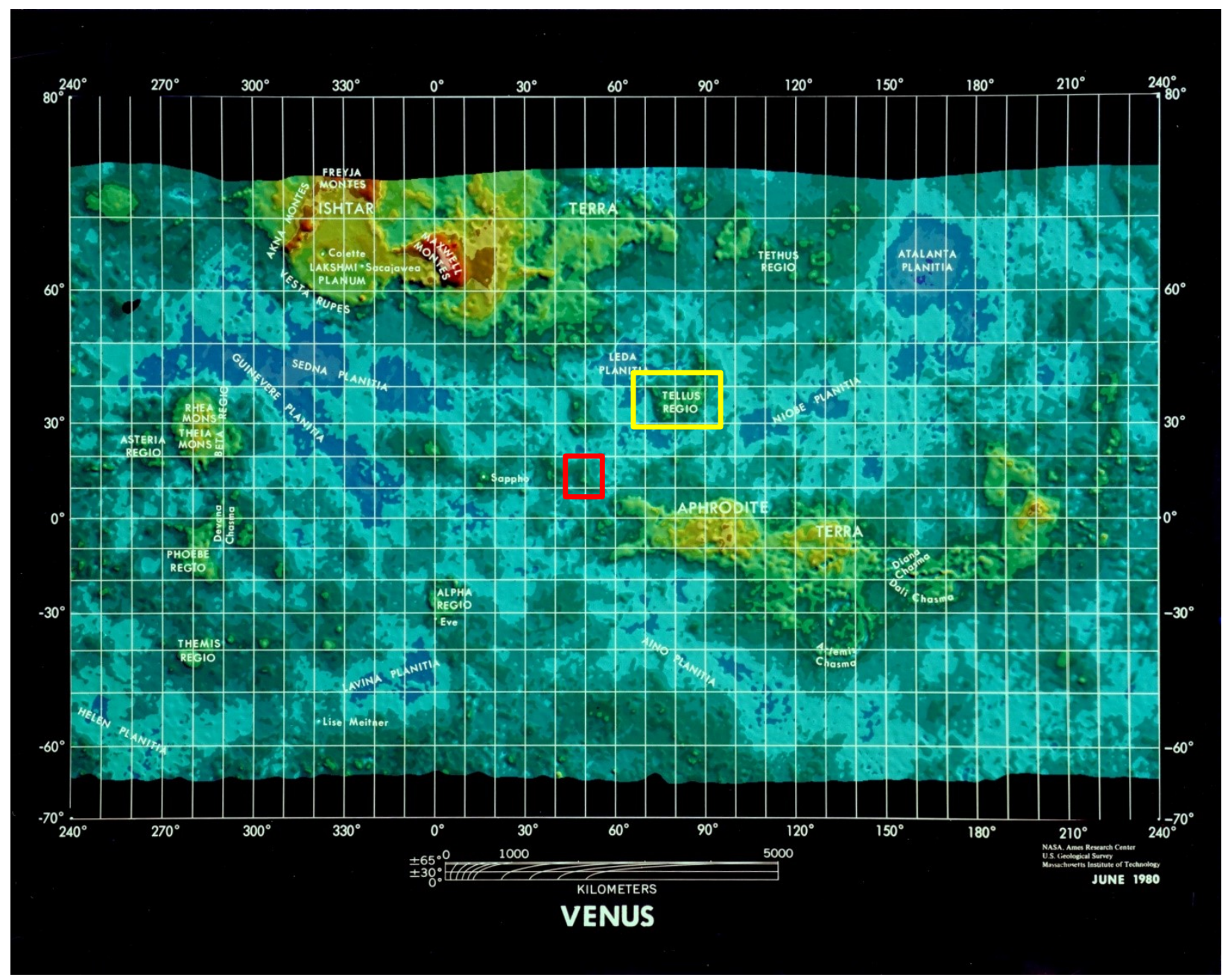

Figure 1.3: Global topography of Venus. Red regions represent areas of topographic highs and darker blue regions represent areas of topographic lows. Tesserae are generally associated with topographic highs (Bindschadler et al., 1992 a, b). Red box locates Salus Tessera, a key study area in this thesis. Yellow box locates Tellus Regio, discussed in Chapter 3. Image source: http://ails.arc.nasa.gov/ails/?v=thumbs\&st=1\&so=unsorted\&page=1\&r=0\&qs=AC78$9135 \& \mathrm{x}=0 \& \mathrm{y}=0$. 
Deformation structures seen on tessera mostly consist of normal faults, thrust faults, folding or a combination (Solomon et al., 1991). Large tesserae (e.g. Aphrodite Terra) commonly consist of sets of presumably contractional ridges and troughs that are crosscut by extensional fractures or grabens (Hansen, 2000). Some large tesserae also contain long, narrow, steep-sided depressions referred to as "ribbon structures" by some authors (Hansen and Willis, 1996; Hansen and Willis, 1998). They differ from grabens by possibly being bound by vertical or nearly vertical fractures rather than by the inward dipping faults seen in grabens (Hansen and Willis, 1998). However, a new model (Hanmer, 2020) suggests that ribbon structures can be interpreted as grabens overlying laterally propagating mafic dykes.

Multiple models have been put forth to explain the formation of tesserae (Solomon, 1993; Turcotte, 1993; Hansen et al., 2000; Romeo and Turcotte, 2008). Formation by mantle downwelling is the most currently accepted model (Gilmore et al., 1998) resulting in compression and thickening of the crust. In this model, compression is followed by isostatic rebound due to the thickening and delamination of the mantle lithosphere thus producing extensional features on tesserae (Gilmore et al., 1998). However, the resulting topography according to this model would suggest a domical shape instead of the flat-topped plateau observed (Romeo and Turcotte, 2008). Hansen (2006) rejected the downwelling model and proposed a new, catastrophic model where crustal plateaus were formed by huge lava ponds generated by massive mantle melting due to large bolide impacts on a thin ancient lithosphere. This model generates questions about whether large bodies can melt a large enough portion of the mantle to generate sufficient volumes of magma. (Ivanov and Melosh, 2003). More recent literature is suggesting tessera formation via lateral accretion of belts (Gilmore and Head, 2018). For instance, detailed analysis of Tellus Regio (Gilmore and Head, 
2018) suggests the SW portions of the tessera were separated at some point by volcanic plains and subsequently accreted together during a compressional event. This is supported by the presence of an interior, and indenter and a ridge (Senske, 1999) within the tessera.

One fundamental assumption in the study of tesserae has been that the current hyper warm conditions $\left(450^{\circ} \mathrm{C}\right)$ that are currently characteristic of Venus also applied during the time of tesserae formation. However, new climatic models (e.g. Way et al., 2016) suggest Earth-like conditions prevailed on Venus during tesserae time and that the climate transitioned to the hyper warm conditions as a result of runaway greenhouse warming associated with massive $\mathrm{CO}_{2}$ release during later voluminous and widespread flood volcanism. A key test of this model is to investigate the tessera terrains in detail and consider evidence of erosion, which would be indicative of pre-global warming conditions.

\subsection{Literature Review}

\subsubsection{Magellan Mission}

NASA's Magellan spacecraft (Figure 1.4) was launched from the Kennedy Space Center in Florida on May 4th, 1989. It entered Venus' orbit on August 10th, 1990 and began mapping the Venusian surface using Synthetic Aperture Radar (SAR) imaging at a resolution of $\sim 75-$ $100 \mathrm{~m} /$ pixel (Saunders et al., 1992). Along with SAR images, the spacecraft was also used to measure the topographic relief, radar reflectivity, surface slope, radio-thermal emissivity as well as gravity (Tanaka et al., 1993). The first orbital cycle, which orbited for 8 months, captured $84 \%$ of the planet using left-looking radar. The incidence angle ranged from 16.5 degrees at the north pole to 45.7 degrees at periapsis. Immediately following cycle 1 , cycle 2 (right-looking radar) mapped approximately 50\% of the planet's surface. This second cycle 
was focused in the southern-hemisphere and covered two major gaps in the previous cycle. The incidence angle was about 25 degrees from $75 \mathrm{~N}$ to $55 \mathrm{~S}$ latitude, and then decreased to 12.7 degrees at the south pole. The final cycle (cycle 3) which was left-looking, filled in many of the remaining gaps before the completion of the mission (Saunders et al., 1992). The incidence angle reached a maximum of 25.6 degrees at $15 \mathrm{~N}$. Part of the cycle was geared towards coverage of Maxwell Montes, from $75 \mathrm{~N}$ to $20 \mathrm{~N}$ at incidence angles from 27 to 36 degrees. The Magellan mission mapped a combined total of $98 \%$ of the planet's surface. The spacecraft was commanded to plunge into the atmosphere to gather aerodynamic data, which brought the mission to its end as the spacecraft burned up.

The high-resolution radar images of the Venusian surface showed evidence of extensive mainly basaltic volcanism (covering $85 \%$ of the surface) and highland "continents" that include highly deformed structures known as tesserae (covering $8 \%$ of the surface). The mission also revealed a lack of erosion and plate tectonics. 


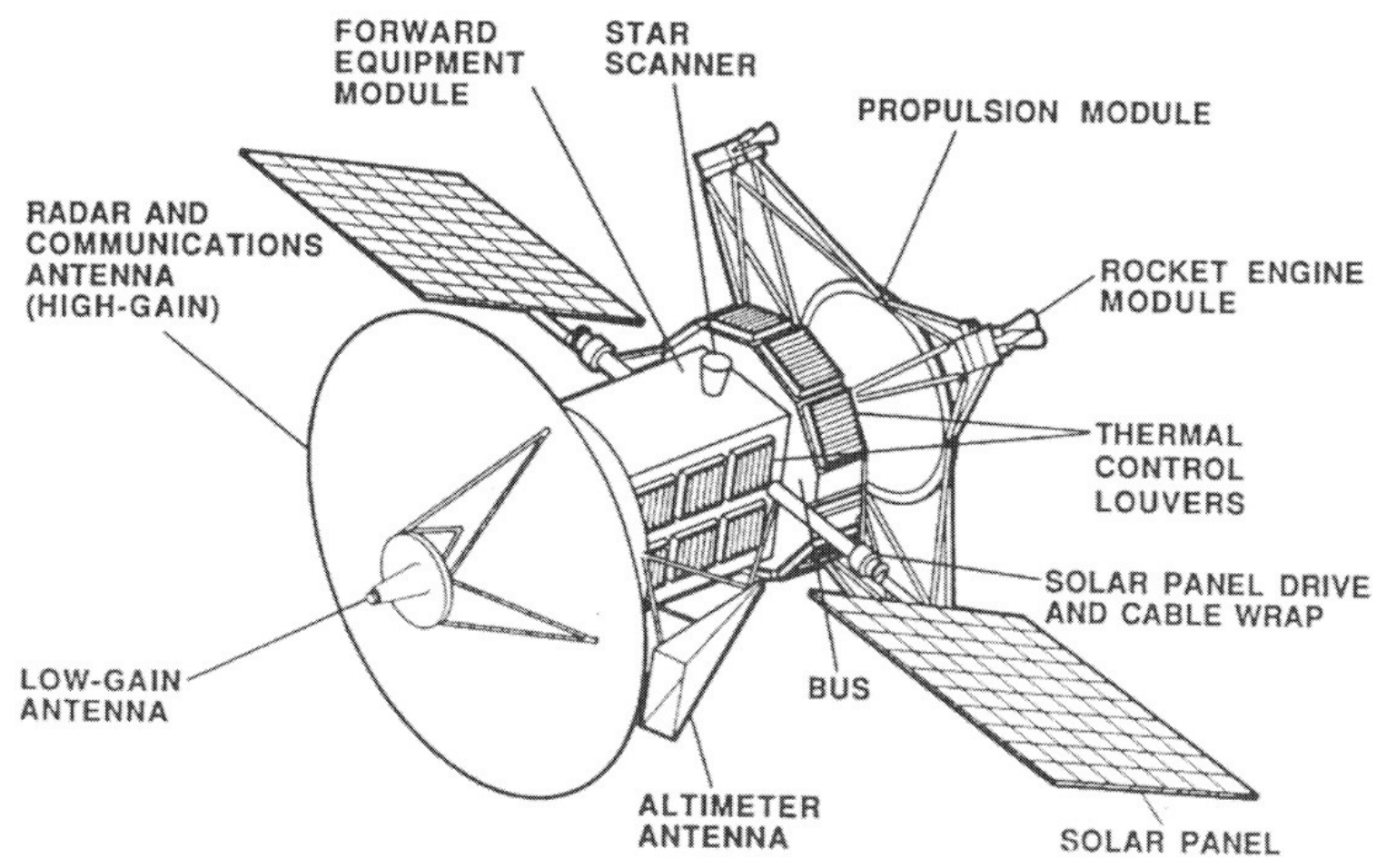

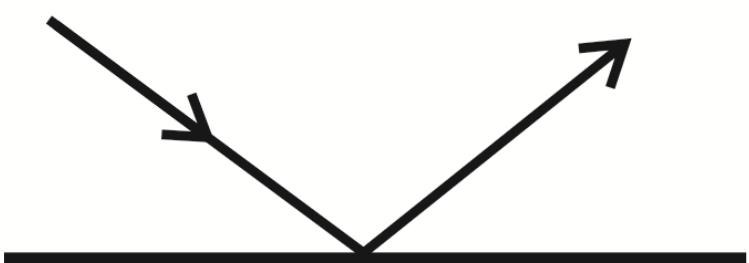

Smooth: Radar signal reflects away from spacecraft, no reflections detected by receiver; image appears dark.

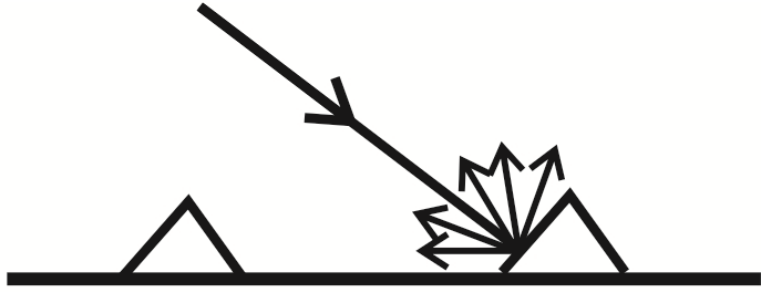

Rough: Radar signal scatters against rough or uneven surfaces, reflections detected by receiver; image appears bright.

Figure 1.4: Schematic diagram of the Magellan spacecraft (Top) Source: NASA/JPL. Diagram representing microwave radar pulses reflecting off various surfaces (Bottom) (Graff, 2016). 


\subsubsection{Geological Mapping}

The publication of high-resolution Magellan SAR data by the United States Geological Survey (USGS) has allowed for the detailed mapping of various geological features seen on the Venusian surface. This ongoing process includes the global mapping project managed by the USGS, where the surface is subdivided into 62 quadrangles (Figure 1.5) that have or will be assigned to a scientist for detailed mapping. In addition, regional mapping has also occurred in parallel with the USGS global mapping project. For instance, quadrangle V-32 has been mapped by a member of the Carleton University Venus Working Group (Bethell et al. 2019). In addition, Ivanov and Head (2011) have produced a global geological map of Venus, briefly describing the different features seen on the surface and their implications.

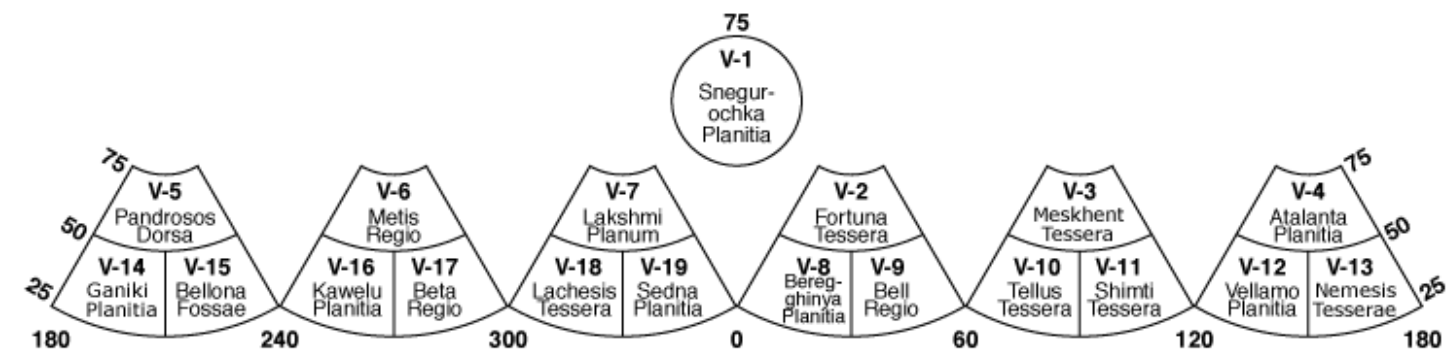

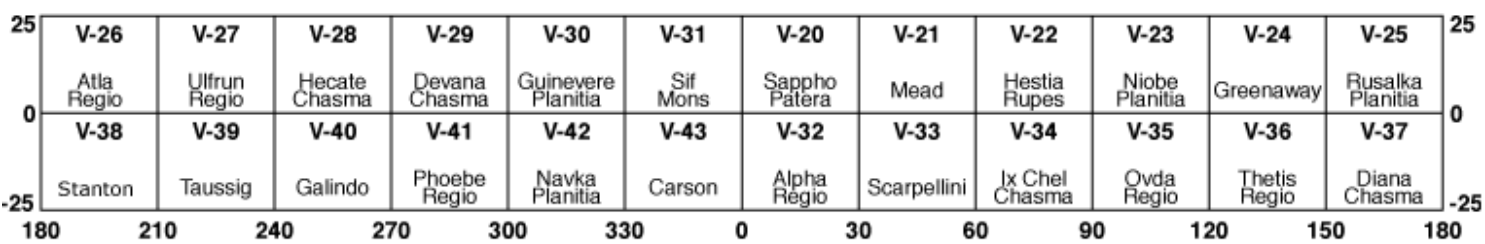

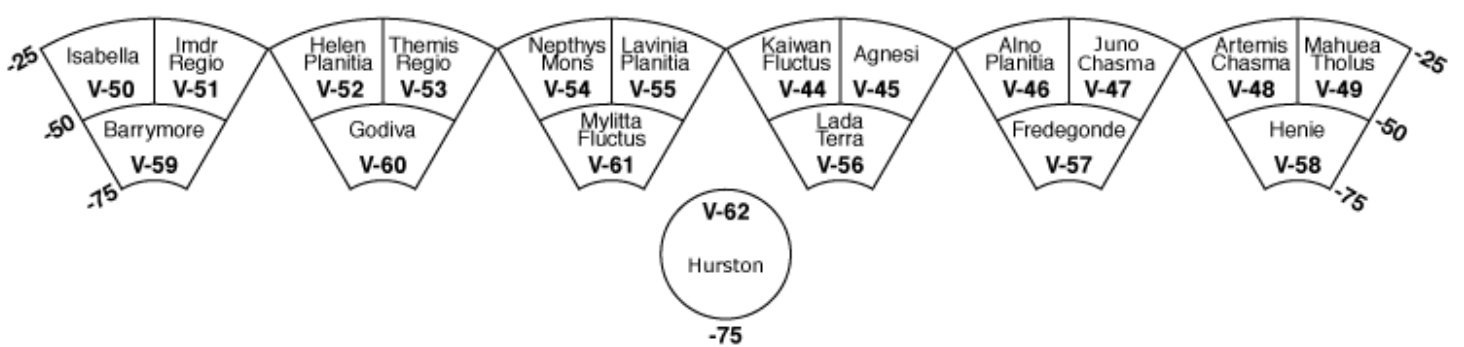

Figure 1.5: Outline of 62 quadrangles subdividing the Venusian surface for detailed mapping (Scale: 1:5,000,000). Source: USGS/IAU. 


\subsubsection{Carleton University Venus Research Group}

Over the past nearly two decades, there has been a team dedicated to mapping Venus at Carleton University. Research was initially focussed on graben fissure systems which on Venus represent the surface expression of underlying dyke swarms (Grosfils and Head, 1994a; Ernst et al., 1995b, 2001, 2003), and dyke swarms represent feeder systems to flood basalts (Ernst and Buchan, 1997a, b, 2001). Graben-fissures can be identified on SAR images as radar-bright lineaments and are commonly seen to exhibit radiating, linear and circumferential geometries (Ernst et al., 1995a,b, 2001, 2003; Ernst and Buchan, 2001; Studd et al., 2011; Grosfils et al., 2014; Lu, 2014; Graff et al., 2018). By combining regional distribution maps of graben-fissure system maps and a global geological map produced by Ivanov and Head (2011), this research aims to provide a better understanding of the planet's intraplate magmatic processes and evolution through time.

The Carleton University Venus Research Group mapped graben-fissure systems in Nephthys Mons Quadrangle (V-54) (Blair and Ernst, 2002), Guinevere Planitia and Beta Regio (Ernst et al., 2003), Ulfrun Regio (Studd et al., 2011), Idunn Mons and Mielikki Mons areas (Davey, 2012), the Mead Quadrangle (Lu, 2014), Parga Chasma (Graff et al., 2018) and in the Decerto corona/Kallisto Vallis volcanic centre (MacLellan and Ernst 2019). In recent years, the Group has expanded geologic mapping beyond graben-fissure systems, to include themes such as pit crater chains (Davey, 2012), rift systems (Graff et al. 2018), lava flow fields (Lee et al., 2019; MacLellan and Ernst 2019), fluvial erosion on tesserae (Khawja et al, 2019), and coronae structures (Bethell et al., 2019). As mentioned above Bethell et al. (2019) has mapped the Alpha Regio quadrangle (V-32) of Venus. 


\subsection{Research Objectives and Structure of the Thesis}

The overarching goal of this thesis project is to analyze tesserae in detail and explicitly consider, for the first time, the role of water erosion. This present research is divided into two major aspects: chapter 3 considers evidence for erosion in tesserae and chapter 4 expands the interpretation of lineaments sets that characterize tesserae in view of possible erosion and provides a method to calculate the orientation of planar geological features associated with lineaments.

Chapter 2: Provides an overview of the mapping methodology used in this thesis and Chapters 3 and 4 address the research objectives.

Chapter 3: Due to current high surface temperatures $\left(\sim 450^{\circ} \mathrm{C}\right)$, it is generally assumed that water erosion did not operate on Venus, and there is abundant evidence for widespread volcanic resurfacing unaffected by erosion. Evidence for the absence of erosion includes features such as flow fields (Magee and Head, 2001) which exhibit simple superimposition of flow units, preservation of the surface expression of widespread shallow thrust faults called wrinkle ridges (Solomon et al., 1999), graben-fissure systems (Grosfils and Head, 1994), and lava channels (Oshigami et a., 2009). However, recent global circulation models (Way et al., 2016; Kane et al., 2019) have suggested the possibility of Earth-like climatic conditions on Venus for much of its earlier history prior to runaway greenhouse warming, suggesting fluvial erosion during tesserae time. Chapter 3 focuses on tesserae margins that were partially flooded by younger lava flows, where volcanic flooding provides a locally consistent horizontal surface, used to distinguish elevated peaks and ridges from valleys. 
Evidence of erosion of tesserae provides evidence to support climate models suggesting a cool, wet climate on early Venus.

Chapter 4: Tesserae are characterized by a complex pattern of families of lineaments which can be straight or curved. They are generally interpreted as representing the surface trace of tectonic structures such as fissures, fractures, grabens, and fold crests. Single lineaments can represent fractures (also fissures and graben) that are expected to appear as thin, and straight or anastomosing lines. Single lineaments can also represent fold crests, which are expected to be wide, and straight or curved. Fractures are typically marked by a sharp zone of radar brightness and overall high contrast with surrounding areas, whereas folds are radar bright along one side and have a gradual brightness transition across them. Building on the evidence for erosion developed in Chapter 3 then the range of interpretations for these lineament sets can be expanded to include shallow dipping sequences of flood basalts, and sedimentary sequences that have been differentially affected by erosion. As a contribution to this expanded analysis of lineament patterns in tesserae, this study also introduces principal component analysis as a methodology to calculate strike and dip of these types of planar features associated with lineaments.

Chapter 5: This chapter summarizes the main findings in Chapters 3 and 4 and suggests avenues for future research. 


\section{Chapter: Methodology and Study Area}

\subsection{Magellan Data}

All SAR images used in this research were obtained from the Magellan Mission and were collected and organized by the USGS (https://astrocloud.wr.usgs.gov), providing the basemaps needed for the detailed analysis of tesserae. Raw SAR images were processed from individual orbital cycles into strips known as F-BIDRs (full resolution basic image data records), which were then assembled to create F-MIDRs (full resolution mosaicked image data records). FMAPS (full resolution radar maps) were released by the USGS at a resolution of 75-100 m/pixel which includes coverage of both left-looking and right-looking radar profiles from all three mapping cycles. The intensity (radar bright vs radar dark) of a pixel is determined by the amount of reflectance and is a function of surface roughness and orientation with respect to the transmitter. Radar bright images represent rough surfaces, or surfaces facing the spacecraft receiver, while radar dark images represent surfaces composed of smooth material (Figure 1.4).

The Global Topographic Data Record (GTDR) (e.g. Figure 1.3), also known as the Magellan Global Topography, was released in 1997 using radar altimetry measurements. These data have a horizontal resolution of 10-20 km and vertical resolution of 50-100 m (Ford and Pettengill, 1992). A new set of higher resolution topographic data was developed by Herrick et al. (2012), using Magellan SAR stereo-derived data (Figure 2.1), produced by combining cycle 1 and cycle 3 data. This resulted in a topographic dataset with a 1-2 $\mathrm{km}$ horizontal resolution which allows for detailed interpretations and modelling on regions that exhibit complex deformation (e.g. tesserae). Unfortunately, the new data set is constrained by the 
limited coverage from cycle 3 of the Magellan mission (20\% of the planet) and the data gaps are filled in using gridded Magellan original altimetry.

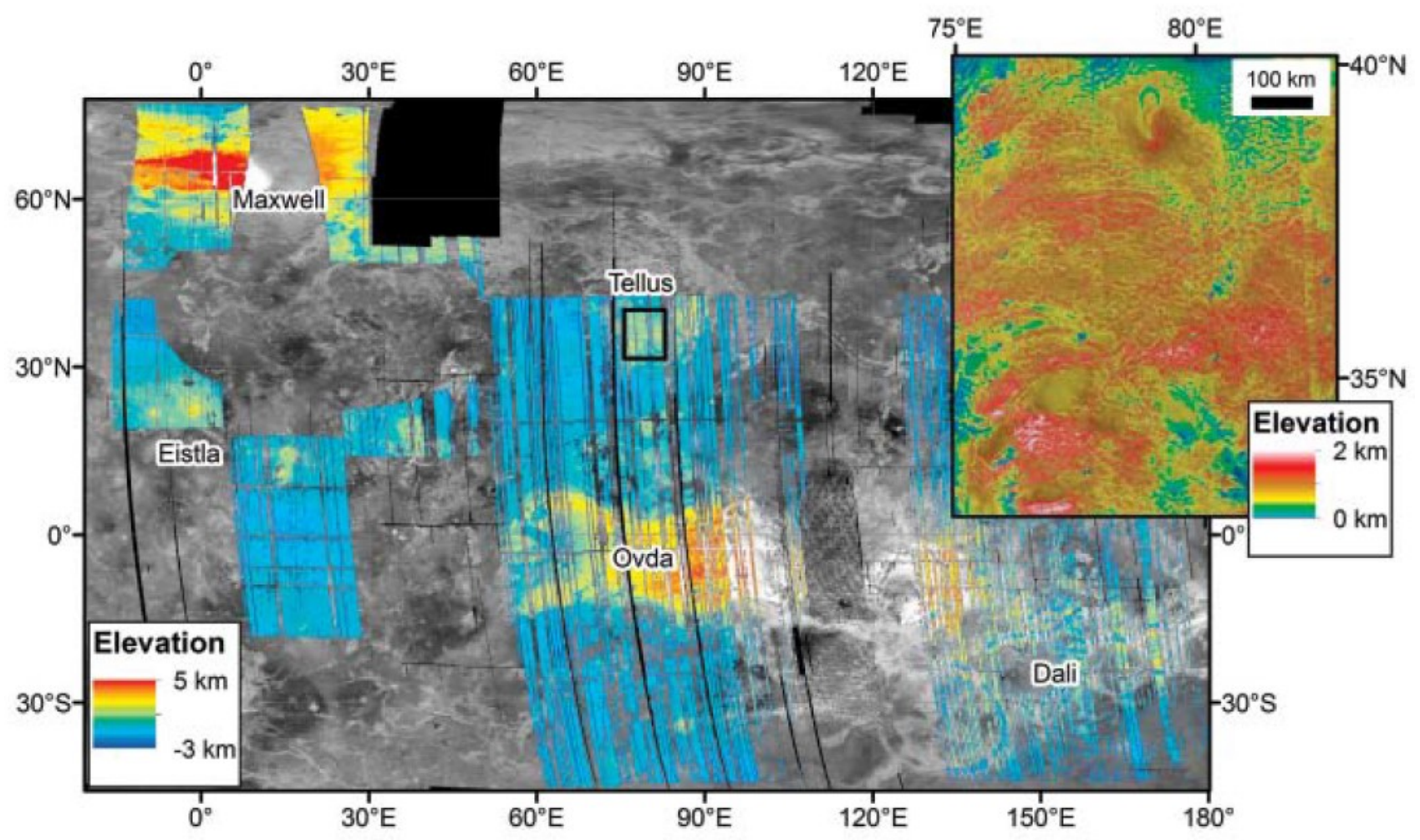

Figure 2.1: Global coverage of the stereo-derived topography (combined Cycles 1 and 3) overlain onto Magellan SAR imagery (Cycle 1). Data are represented with colour coded elevation (e.g. top right image) and are elevation values are quoted relative to the mean planetary radius. Source: Herrick et al. (2012). 


\subsection{Mapping and Imaging Software}

\subsubsection{ArcGIS}

Mapping of tesserae (extensional features, compressional features, flooded areas, folds, etc.) was completed using ArcGIS v10.6 software (https://desktop.arcgis.com/en/arcmap/). All basemaps imported into the program were downloaded in a sinusoidal map projection where each raster was georeferenced using the 'GCS Venus' coordinate system. The ArcCatalog function allows for the creation of editable layers known as shapefiles, useful for tracing out the detailed radar-bright linework corresponding to lineaments.

\subsubsection{JMARS}

JMARS (java mission-planning and analysis for remote sensing) is an essential GIS software used for viewing and analyzing remote sensing data from a variety of sources. Developed by Arizona State University's Mars Space Flight Facility, JMARS was made publicly available in 2003 after the addition of mission data products from other planetary bodies including Earth, the Moon, Mercury, Jupiter, Saturn (and their moons), selected asteroids and Venus, the focus of this research. The Venus datasets available on JMARS include Magellan SAR FMAP left/right/stereo mosaics at the resolution of 75-100 m/pixel, elevation (meters), shaded relief, slope and stereo-derived topography. The allotment of readily available scientific data, customizable spatial analyst features, and import/export capabilities made JMARS a valuable tool throughout the study, particularly for reconnaissance observations. JMARS was also used to create the topographic profiles across and along lineament sets in Chapter 4 and from which the orientation of planar features associated with lineaments sets was calculated. 


\subsubsection{Corel Draw}

Corel Draw is a graphics editor that was used to format final figures, tables and graphs. The "outline trace" tool was used as a helpful visualization method that involved grouping pixel intensities from SAR images into multiple discrete bins and generating a map that provides improved resolution of lineament trends in tesserae.

\subsubsection{XLSTAT}

XLSTAT is a powerful statistical analysis tool that can be added to Microsoft Excel. It can be used to analyze, customize and solve over 220 statistical problems in an efficient and userfriendly way. XLSTAT was used to conduct principal component analyses (PCA) to determine dip of planar features associated with surface lineaments on tesserae (Chapter 4).

\subsection{Study Area}

Chapter 3 incorporates images of tesserae from across Venus, but Chapter 4 focusses on a particular tessera, Salus, which lies between $42^{\circ}$ to $56^{\circ}$ latitude and $2^{\circ}$ to $-8^{\circ}$ longitude, along the boundary between the Scarpellini (V-33) and Mead (V-21) quadrangles. This small tessera which has a center latitude and longitude of $48.5^{\circ}$ and $-1.5^{\circ}$, respectively, and spans $850 \mathrm{~km}$ in diameter, is the focus of detailed lineament analysis in Chapter 4. It is also used as one of the examples for erosional features in Chapter 3. 


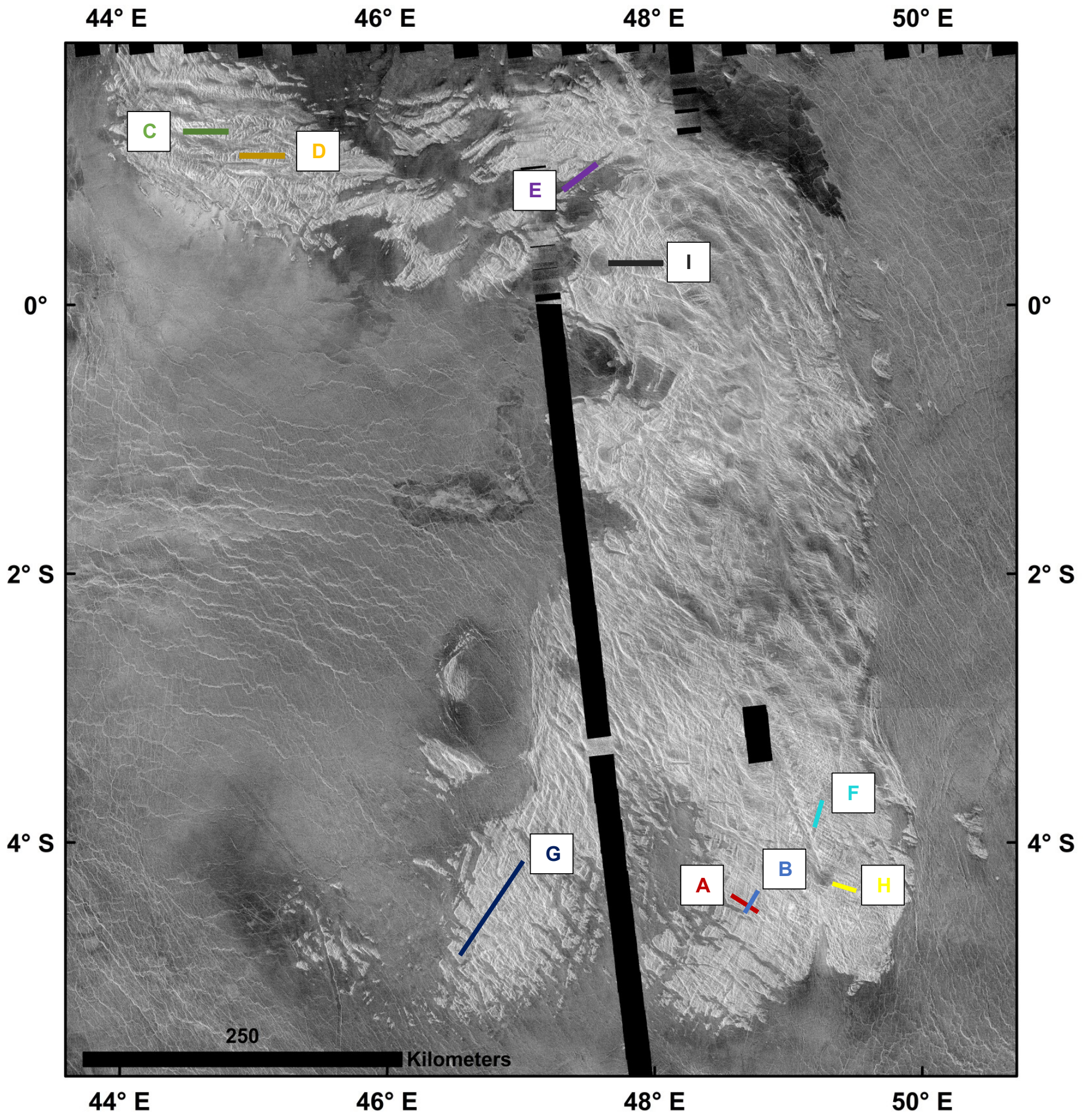

Figure 2.2 SAR image of Salus Tessera. Location shown in Figures 1.2 and 1.3. The locations (labelled lines) for the topographic profiles shown in chapter 4. 


\section{Chapter: Fluvial Erosion on Venus}

\subsection{Introduction}

There is some evidence for surface mineralogical changes due to weathering in the VIRTIS (Visual and Infra-red Thermal Imaging Spectrometer) data from the (2005 - 2014) Venus Express spacecraft (e.g. Smrekar et al. 2010). However, it is generally accepted that the surface of Venus does not display evidence for extensive erosion, which is convincingly true for stratigraphically younger lobate flows which exhibit simple superposition of flow units and have radar backscatter properties consistent with primary flow morphology and rheology (Byrnes and Crown, 2002; Zimbelam, 2003). Additional features such as shallow thrust faults called wrinkle ridges (Solomon et al., 1999; Bethell et al., 2020), graben-fissure systems (Ernst et al., 2003), and lava channels (including canali and sinuous rilles) (Bray et al., 2007; Oshigami et al., 2009) all have surface topographic signatures that would have been lost if fluvial erosional processes had been active. Impact craters are mostly pristine except where partially flooded by later lavas (Whitten and Campbell, 2016). These observations imply a lack of hydrological erosion on Venus, consistent with the planet's current high surface temperature of $450 \mathrm{C}$.

\subsection{Erosion on Venus}

There are 4 major reasons to expect erosional features in the stratigraphically oldest preserved units on Venus, tesserae:

1) The assumption of the absence of erosion in the tesserae needs to be questioned in light of recent climatic modelling of Venus which suggest that Earth-like conditions could have 
been present for most of Venus history but that a runaway greenhouse effect changed Venus' climate catastrophically and led to loss of water (Ingersoll., 1969; Way et al., 2016; Kane et al., 2019; Way et al., 2020). The cause of this greenhouse effect is linked to catastrophic $\mathrm{CO}_{2}$ degassing during global volcanic resurfacing. Under the volcanic interpretation, the timing of the climatic transition would correlate with the onset of major volcanic resurfacing at approximately $700 \mathrm{Ma}$. Therefore, the stratigraphically earlier tesserae might thus have formed under climatic conditions, where liquid water was present, allowing for the possibility of fluvial erosion.

2) The tectonic complexity of tesserae (e.g., Hansen and Willis, 1996), including evidence of accretion tectonics (Gilmore and Head, 2018) suggests deformation at depth followed by unroofing and exposure at the surface (Ernst et al., 2019). However, this hypothesis remains to be tested by modeling the deformation of mafic and felsic units under a range of atmospheric pressure and temperature conditions relevant to Venus.

3) Lineaments with irregular curvilinear patterns in tesserae may be indicative of shallow-dipping planar layers that follow undulating topography caused by erosion (e.g. in Alpha Regio) (Byrne et al., 2019, Byrne et al., 2020; Khawja et al., 2020 and Ernst et al., 2020). By analogy with Earth, such shallow-dipping layers could be a sequence of volcanics (i.e., flood basalts, rhyolites, or pyroclastics) and/or represent sedimentary units, or perhaps even layered intrusions.

4) Present-day topographic variations observed in tesserae can be interpreted as due to water erosion (Ernst et al., 2019; Khawja et al., 2020; Ernst et al., 2020). 
This Chapter focuses on the fourth point by addressing the causes of observed topographic variations in tesserae. This Chapter first addresses whether the variations can be due to primary topographic variations due to folding or faulting. Once concluding that erosion is required, the presence of water, wind and/or glacial erosion are assessed.

\subsection{Topographic Variations}

In a search for features indicative of erosion it is necessary to consider the scale of relevant topographic features vs the resolution of the topographic data.

Figure 3.1 shows a topographic profile across Tellus Regio where, across distances of many hundreds of kilometres there are topographic variations up to three kilometres. Most dramatically, the Western Margin and Eastern Margin terranes are higher and interpreted as thrust belts onto an older crustal block. Thus, there are major topographic changes of up to several kilometres that can represent terrane accretion tectonics (Gilmore and Head, 2018). On this large scale, it is also possible to envision tectonic unroofing along faults that bring deeper deformed units upward and then exposes them by erosion. However, the effect of erosion to modify the structures produced by accretion tectonics was not discussed by Gilmore and Head (2018). On the much more local horizontal scale of a few tens of kilometres, the topographic variations are often less than $100 \mathrm{~m}$. It is this more local-scale small-magnitude topographic variations that are the focus of this Chapter. 

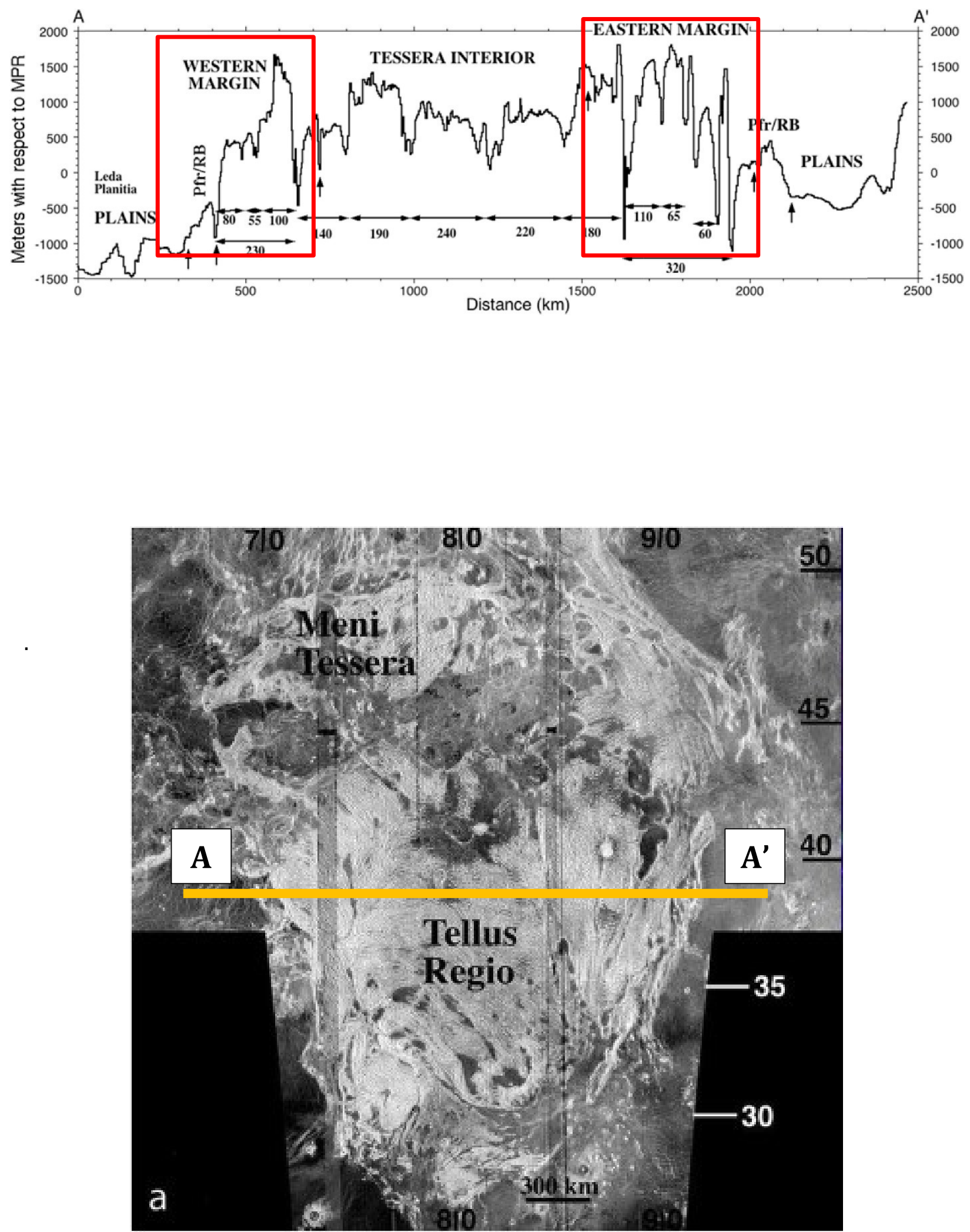

Figure 3.1: Top: east-west topographic profile of Tellus Regio. Western and eastern margins of Tellus Regio (red boxes) may represent terranes that have been accreted and uplifted (Gilmore and Head, 2018) and then subsequently eroded (suggested herein). Bottom: SAR image of Tellus Regio with the trace of topographic profile A to A' (orange line) shown on top. Location on global map is shown in Figures 1.2 and 1.3. 


\subsection{Methodology for Identifying Topographic Valleys}

The scale of the expected topographic variations of tens to hundreds of metres is similar to the resolution of the Magellan data, which (as noted in Chapter 2) has poor vertical and horizontal resolutions of 50-100 $\mathrm{m}$ and $\sim 10-20 \mathrm{~km}$ ('footprint'), respectively. The new higher resolution stereo topographic maps recently produced from combining Cycle 1 and Cycle 3 Magellan SAR data (Herrick et al., 2012), have a similar vertical resolution but an improved horizontal resolution of 1-2 km. The vertical uncertainties of 50-100 m could be small enough for topographic analysis. However, since the horizontal footprint for this elevation estimate is $1-2 \mathrm{~km}$ at best (with the new Herrick et al. (2012) reprocessed data) and at worst, 10-20 km (original Magellan topographic data), it is impossible to uniquely match topography values to distinct features in the Magellan images (which have a 75-100 m pixel resolution). This problem is less severe for the smooth plains areas of Venus where the topography is gently-varying, but is acute for the topographically rough tesserae.

To circumvent the issue of elevation uncertainties, this research applies a technique of only using portions of tesserae that are partially flooded by younger mafic lava flows (Figure 3.2). It is assumed that lavas have flooded these areas to approximately the same level. Therefore, the lava flooding represents a horizontal datum, that clearly identifies the highest peaks and ridges, and distinguishes these from the "valleys' filled by lava flooding. The pattern of the identified valleys can be diagnostic of earlier fluvial erosion processes. 

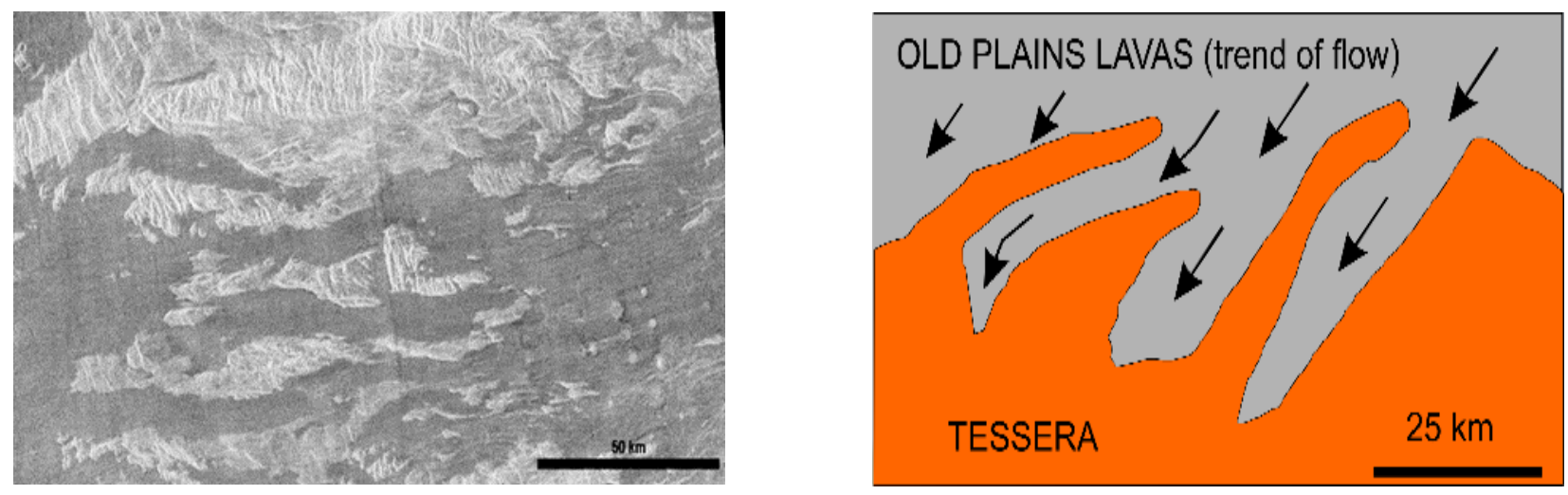

Figure 3.2: LEFT: Magellan SAR image (central coordinates: 61.7E, 6.5S) showing segments of tesserae (light grey) surrounded by plains unit (dark grey). RIGHT: Schematic diagram of tessera terrain (Tt) flooded by lava flows of plains unit (Ps).

To further illustrate the effectiveness of this approach to improve topographic resolution, some terrestrial analogues of 'flooding' of topographic low areas are considered. It can be observed that flooded fjords, nunataks and yardangs appear morphologically similar to tesserae margins partially flooded by lava flow-with water as the datum (for flooded fiords), ice as the datum (for nunataks), and sand as the datum (for yardangs) (Figure 3.3). In each of these examples the geological features above the datum are rendered especially prominent.

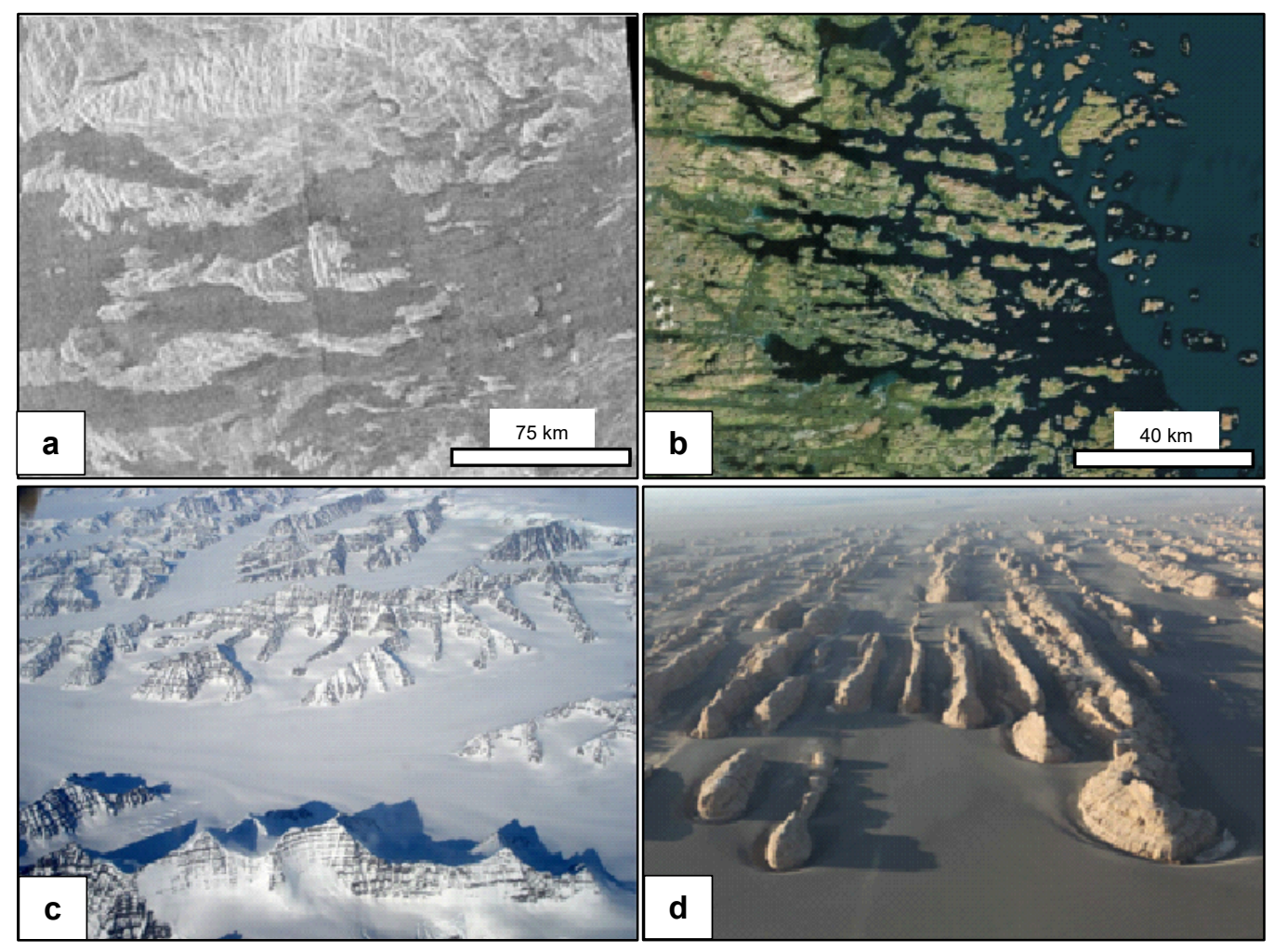


Figure 3.3: Topographic highs emerge above a lower, relatively smooth, datum. A) Magellan left-look SAR image from Venus at $6.5^{\circ} \mathrm{S}, 61.7^{\circ} \mathrm{E}$ (central coordinates) showing portions of tesserae (light grey) surrounded by plains units (dark grey). B) Fjords flooded by water in Nain, Labrador, Canada (Source: Google maps) $\left.\left(56.5^{\circ} \mathrm{N}, 61.7^{\circ} \mathrm{E}\right) \mathrm{C}\right)$ Nunataks (high standing mountains) surrounded by a field of ice and snow $\left(65.4^{\circ} \mathrm{N}\right.$, $37.3^{\circ} \mathrm{W}$ ) https://commons.wikimedia.org/wiki/File:Eastcoastgreenland1.jpg. D) Yardang field bordering the desert of Kumtagh, China $\left(42.7^{\circ} \mathrm{N}, 90.3^{\circ} \mathrm{E}\right)^{3}$, with individual features that are hundreds of metres long.

\subsection{Primary Topography vs Erosion}

In the traditional interpretation of tessera, i.e. in the absence of erosion, the present tesserae surface should only reflect primary topography produced by folding and faulting. Four models are considered when explaining topographic variations in tesserae (Figure 3.4). The first three models explain topography as primary, i.e. only caused by folding or faulting, without any subsequent erosion. The fourth model (Figure 3.4D) requires erosion.

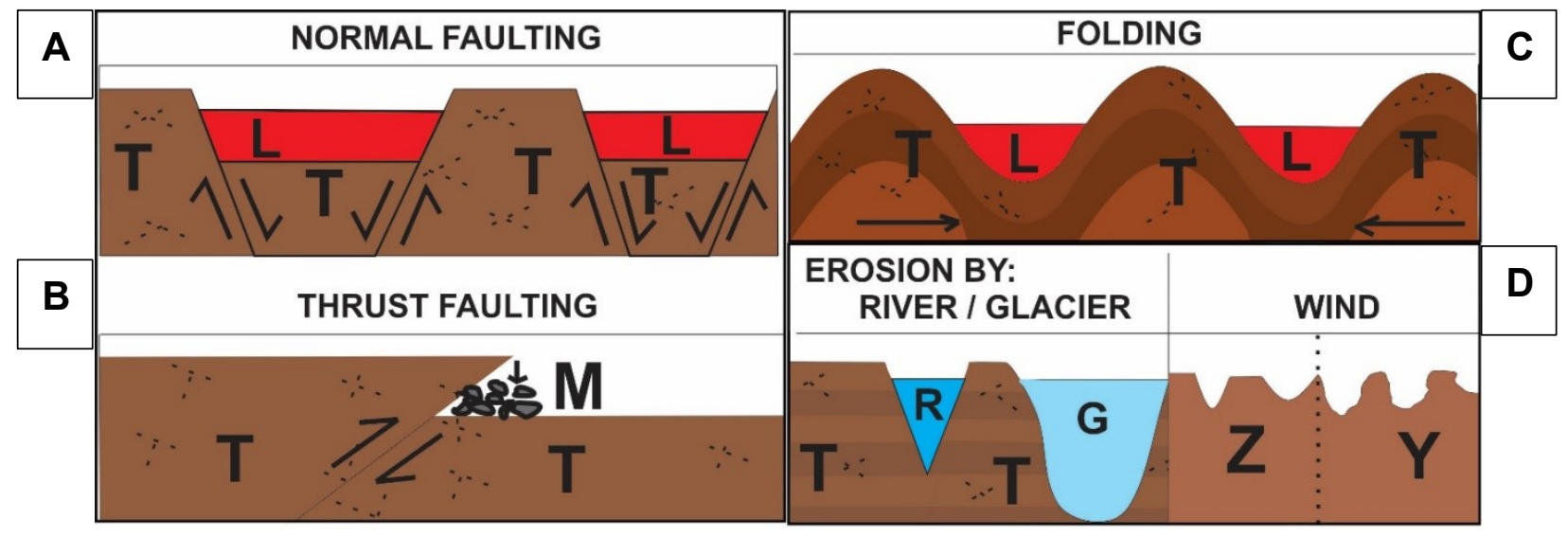

Figure 3.4: Schematic diagrams of three topographic models to explain topographic variations: faulting (normal (A)/thrust (B)), folding (C) and erosion by river/glacier or wind (D). T = tessera, $\mathrm{L}=$ lava flooding, $\mathrm{M}$ = mass wasting, $\mathrm{R}$ = river erosion, $\mathrm{G}=$ glacial erosion, $\mathrm{Z}$ = zeugens, $\mathrm{Y}=$ yardangs. 

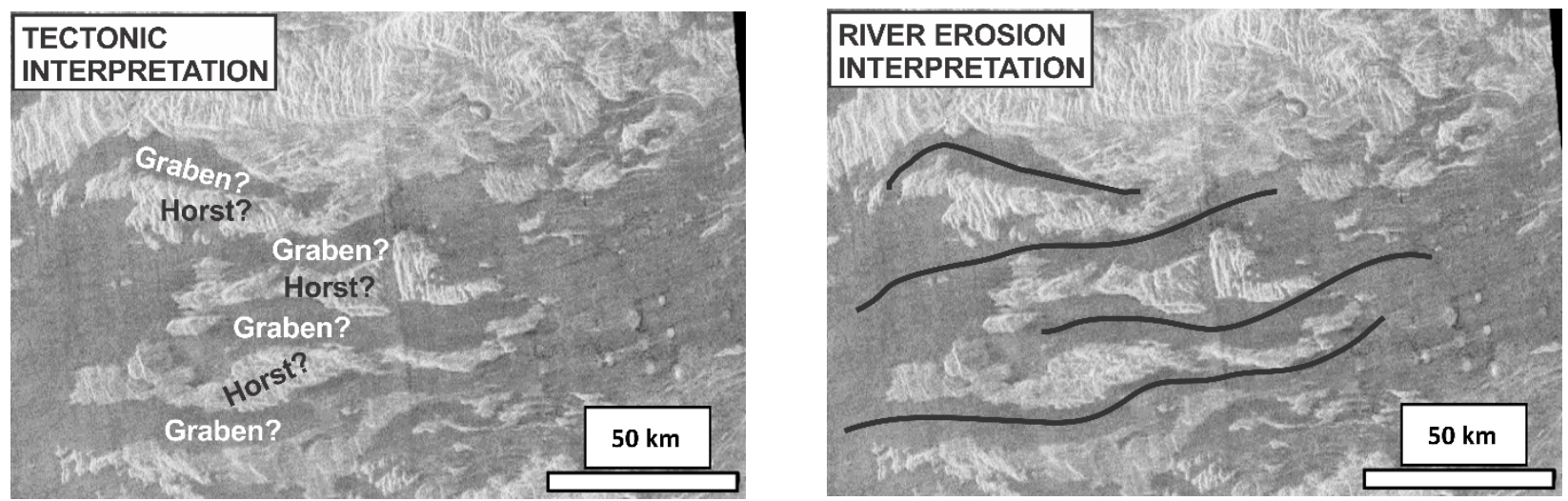

Figure 3.5: Magellan SAR image (61.7E, 6.5S) showing segments of tesserae (light grey) surrounded by plains unit (dark grey). Left: tectonic interpretation. Right: stream erosion interpretation (black lines represent interpreted stream valleys later filled by lava flows). After Khawja et al. (2020).
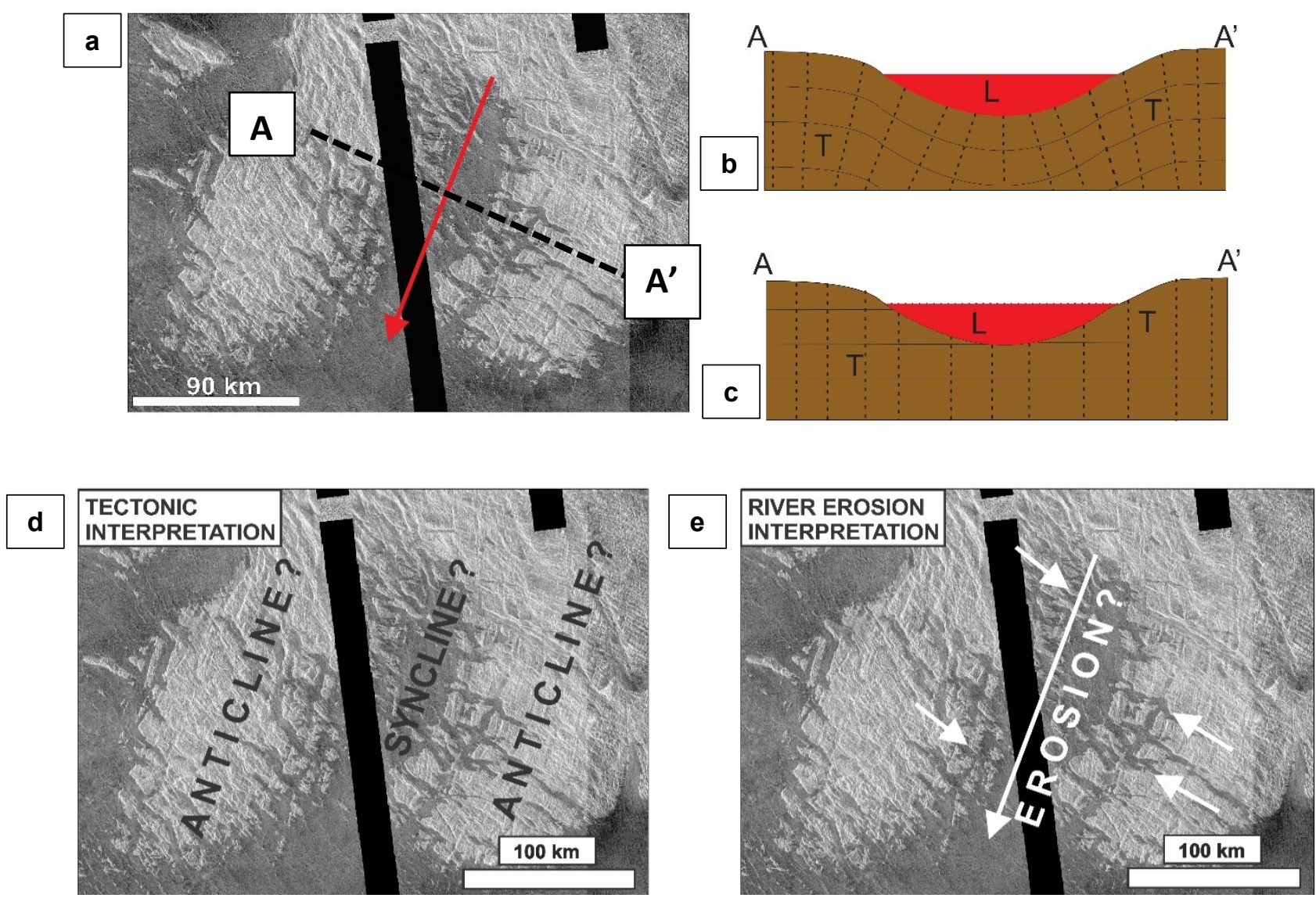

Figure 3.6: a) Left looking Cycle 1 Magellan SAR image (central coordinates $4.4^{\circ} \mathrm{S}, 48.2^{\circ} \mathrm{E}$ ) from the southern part of Salus Tessera, showing a re-entrant (arrow) that has been flooded by younger plains lavas (dark grey). Alternative explanations for cross section A-A': synformal folding (b) erosion (c). Both models (tectonic and erosion) are shown in (d) and (e). Parts (d) and (e) after Khawja et al. (2020). 
Figure 3.5 shows an irregular pattern of tesserae high ground and valleys (marked by lava flooding). In this case, the E-W linear structures on the tesserae tend to be locally oblique to the trend of possible grabens and horsts, and erosion may offer a simpler interpretation.

Eight additional examples of partially flooded tesserae are considered in terms of both purely tectonic and erosional interpretations (Figures 3.6, 3.7 and 3.8). From this perspective, the tessera valley pattern in the first example (Figures $3.7 \mathrm{a}$ and 3.6 ) can be interpreted as a broad synformal flexural fold with a wavelength of $120 \mathrm{~km}$. However, in such a folding model, the adjacent anticlinal portions should exhibit no structures (or perhaps only minor parasitic folds and secondary structures) in the absence of erosion (Figure. 3.6b) which seems at odds with their apparent tectonic complexity. Another structural alternative would be a down-dropped NNE-SSW-trending central block with a width of 30-50 km. The volcanic-flooding pattern, however, does not clearly delineate a simple down-dropped block, and there is no obvious continuation of postulated rift margin structures outside the area of volcanic flooding to the NNE (and such features should be obvious in the absence of erosion). An alternative interpretation is an initial down-dropped block followed by a protracted history of erosion in the direction of the arrow producing a wide valley (Figure 3.6a). Figure 3.7C could be interpreted as a series of parallel graben or as an anticlinal-synclinal sequence with a spacing of 4-10 km. Figure. 3.7D is more difficult to explain structurally but has some resemblance to "chocolate tablet boudinage" structures (Ghosh, 1998). In each of the four examples presented in Figure. 3.7, there are additional generations of superimposed lineaments and surficial irregularities that would require multiple generations of tectonism down to the scale of image resolution $(100 \mathrm{~m} /$ pixel). On the other hand, adding erosion to 
such primary tectonic processes could provide a simpler explanation for many of the topographic complexities.

In summary, tesserae which have been partially flooded by lava flows, exhibit patterns of elevated areas (peaks and ridges) and valley (flooded areas) which at best be only partially explained by primary features (folding and faulting) and there must be a considerable erosion component. The following section examines the stream drainage pattern story to assess the role of water erosion, and the possibility of glacial and wind erosion are considered in sections 3.7 and 3.8 . 


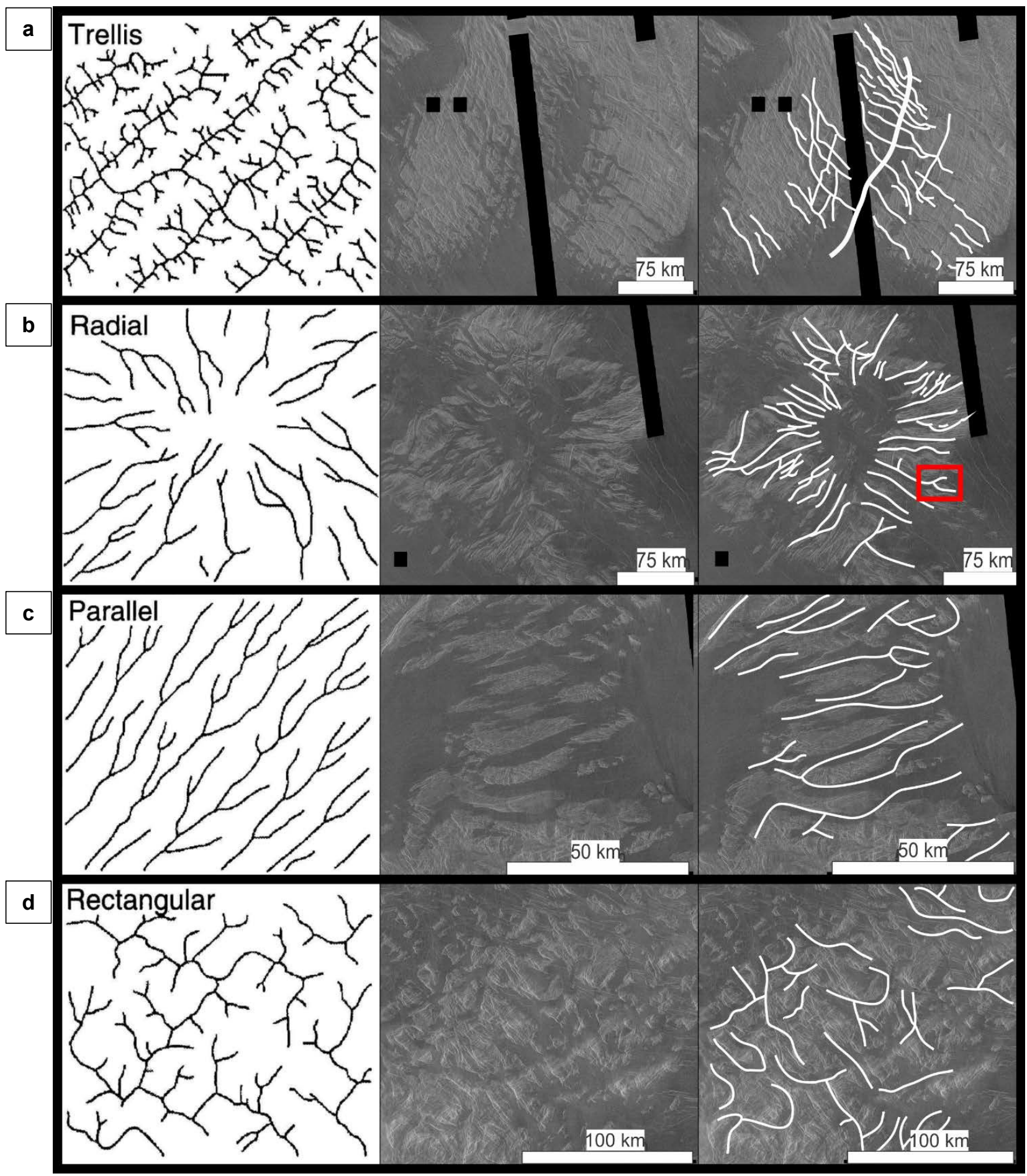

Figure 3.7: Tesserae regions that are partially flooded by mafic flows in interpreted terms of stream drainage patterns. Each row features a Magellan SAR image (centre) on which an interpreted valley pattern is drawn based on the pattern of volcanic flooding (right) and which is approximately matched to major types of terrestrial stream drainage patterns (left). Types of stream patterns on Earth are after Howard (1967) and Bridge and Demicco (2008). Centre locations of SAR images: rows a $\left(4.4^{\circ} \mathrm{S}, 48.2^{\circ} \mathrm{E}\right), \mathrm{b}\left(16.3^{\circ} \mathrm{S}, 57.3^{\circ} \mathrm{E}\right), \mathrm{c}\left(4.6^{\circ} \mathrm{S}\right.$, $\left.62.1^{\circ} \mathrm{E}\right)$ and $\mathrm{d}\left(7.5^{\circ} \mathrm{S}, 68.8^{\circ} \mathrm{E}\right)$. The SAR images are left-looking Cycle 1 from the Magellan mission; black rectangles are gaps in the data. In each image north is to the top. Locations are shown in Figure 1.2. 


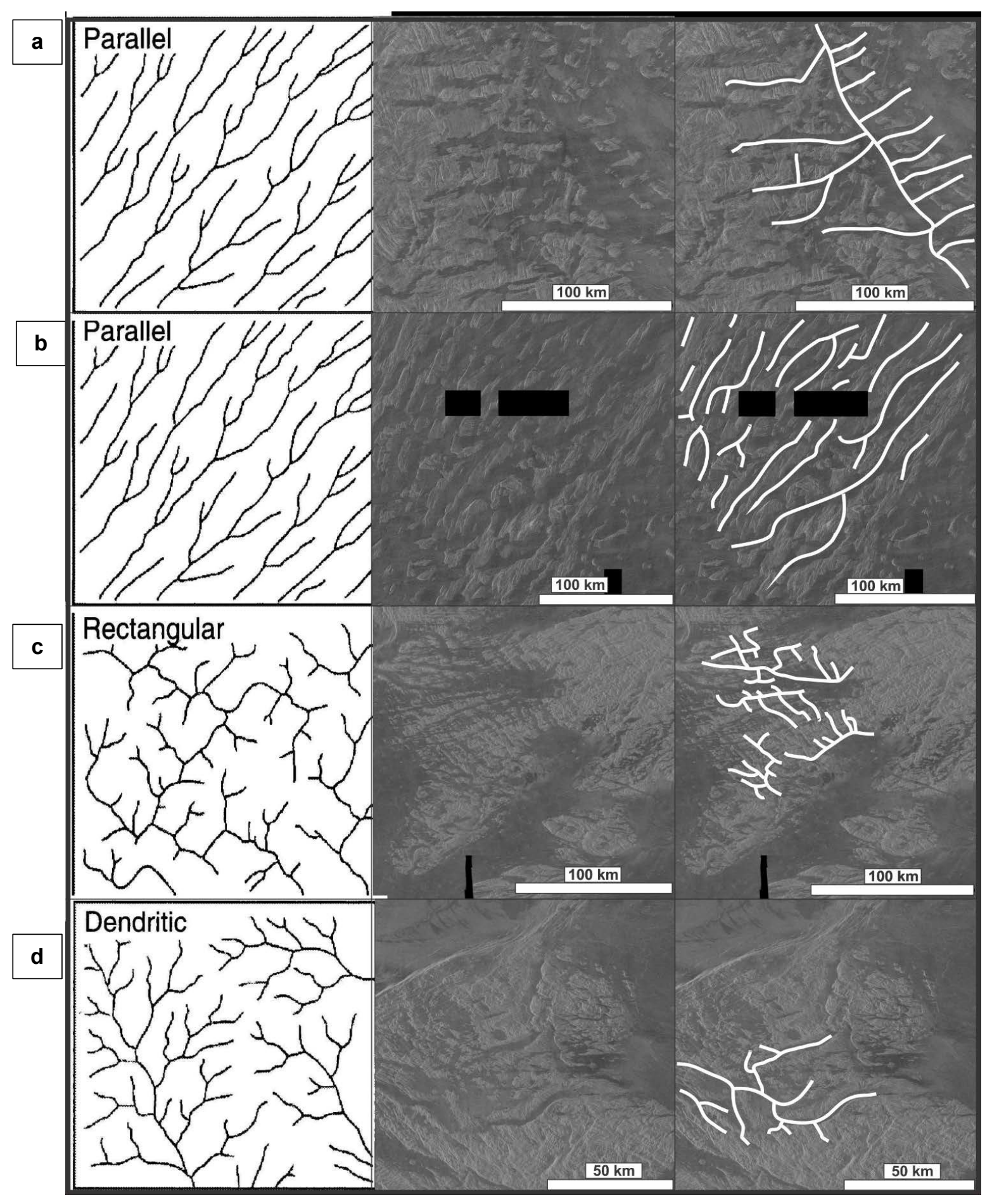

Figure 3.8. Additional examples of tesserae regions that are partially flooded by mafic flows in terms of stream drainage patterns. Each row features a Magellan SAR image (centre) on which an interpreted valley pattern is drawn based on the pattern of volcanic flooding (right) and which is approximately matched to major types of terrestrial stream drainage patterns (left). Types of stream patterns on Earth are after Howard (1967) and Bridge and Demicco (2008). Centre locations of SAR images: rows a $\left(74.4^{\circ} \mathrm{E}, 4.6^{\circ} \mathrm{S}\right), \mathrm{b}\left(69.8^{\circ} \mathrm{E}, 1.1^{\circ} \mathrm{S}\right), \mathrm{c}\left(129.0^{\circ}\right.$ $\left.\mathrm{E}, 50.8^{\circ} \mathrm{N}\right)$ and $\mathrm{d}\left(126.4^{\circ} \mathrm{E}, 48.9^{\circ} \mathrm{N}\right)$. The SAR images are left-looking Cycle 1 from the Magellan mission; black rectangles are gaps in the data. In each image north is to the top. Locations are shown in Figure 1.2. 


\subsection{Water Erosion}

\subsubsection{Comparison with Stream Drainage Patterns}

The valley patterns of the eight tesserae shown in Figures 3.7 and 3.8 are compared with terrestrial stream drainage patterns (Bridge and Demicco, 2008). Notably, the tessera valley patterns are morphologically similar to five of the six recognised terrestrial stream drainage patterns: "trellis", "radial”, "parallel”, "dendritic” and "rectangular" (the additional pattern that is not recognised in these tessera examples is the "annular" pattern). The morphological and dimensional similarity between these tessera valley patterns and terrestrial stream drainage patterns are consistent with a scenario under which fluvial erosion contributed to shaping tessera topography.

Terrestrial stream systems can be quantified in terms of width, length, changes in orientation, sinuosity, spacing, degree of interconnectivity, etc. Such data for Venus tessera valleys would enhance the comparison with terrestrial stream systems. However, the width of lava flooding in the valleys (up to $>50 \mathrm{~km}$ ) should not be interpreted as the width of the postulated stream systems. Depending on their accumulated thickness, the infilling flows could extend up the sides of the valleys, thus obscuring the details of the fluvial system beneath, including evidence of a protracted fluvial history.

\subsubsection{Tear Drop Shaped Island}

A further example of fluvial erosion is offered in Figure. 3.9 where a tear-drop-shaped "island" is apparent in a lava-flooded valley within a tessera. The tear-drop geometry suggests flow from west to east. An interpretation in which the lava flow causes the 
distinctive shape is unlikely since the lava flow was likely emplaced from east to west from the adjacent volcanic plains. On the other hand, the interpretation of flow from west to east would be consistent with a stream system eroding material from the interior of the tessera.

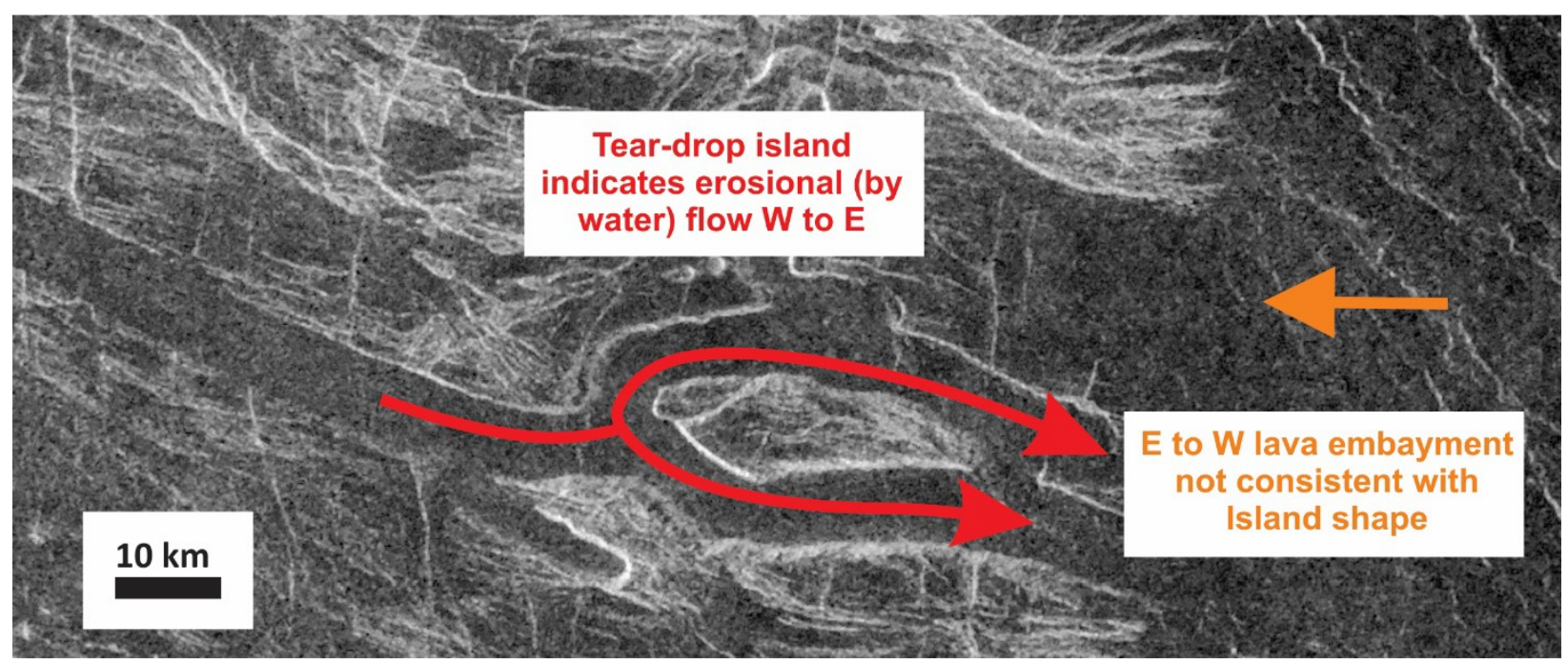

Figure 3.9. Tessera showing a tear-drop-shaped "island" $\left(16.7^{\circ} \mathrm{S}, 058.2^{\circ} \mathrm{E}\right)$ Centre of image is at $16.7^{\circ} \mathrm{S}, 058.0^{\circ} \mathrm{E}$. North is to the top. For location in a broader context see red box in Figure. 3.7B

Wind and ice erosion are next considered.

\subsection{Wind Erosion}

Present-day conditions on Venus do not allow for the existence of liquid water or ice, thus wind erosion is the dominant current style of erosion on the planet. There are two classes of aeolian features in volcanic areas of Venus: depositional and erosional.

Depositional features include parabolic halos, wind streaks, dunes and ergs (dune fields at least $125 \mathrm{~km}^{2}$, (Parrish 2001)). The halos represent impact ejecta material that has been deposited downwind from an impact crater in a parabolic pattern (Ivanov et al., 1992). At least two ergs have been recognized during the Magellan mission: the Aglaonice dune field, which covers approximately $1,290 \mathrm{~km}^{2}$ and the Meshkenet dune field $\left(17,120 \mathrm{~km}^{2}\right)($ Greeley et al., 1992). These seem to be mostly transverse dune fields (with dune crests perpendicular 
to prevailing winds). Despite the many differences in atmospheric conditions between the two sister planets, Venus uses the same mode of wind transportation as Earth (Craddock, 2011) therefore suggesting the dunes have a sand-dominant composition.

From among types of wind erosional features observed on Earth (ventifacts, rock pedestals, zeugen and yardangs) (Figure 3.10), only yardangs have so far been observed on Venus. One example is concentrated in an area $300 \mathrm{~km}$ southeast of Mead crater and average $25 \mathrm{~km}$ long and $0.5 \mathrm{~km}$ wide (Greeley et al., 1992). These features can be distinguished from wind streaks by having well defined boundaries and not originating from (being downwind from) topographic features. The presence of these yardangs suggests the presence of movable deposits that have been eroded over time and indicate wind erosion mechanisms are currently still active and have been active in the past (Basilevsky and McGill, 2007). 


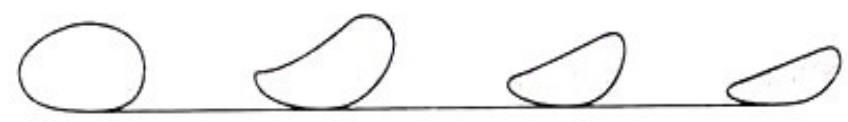

A) Formation of Ventifact

B) Rock Pedestal
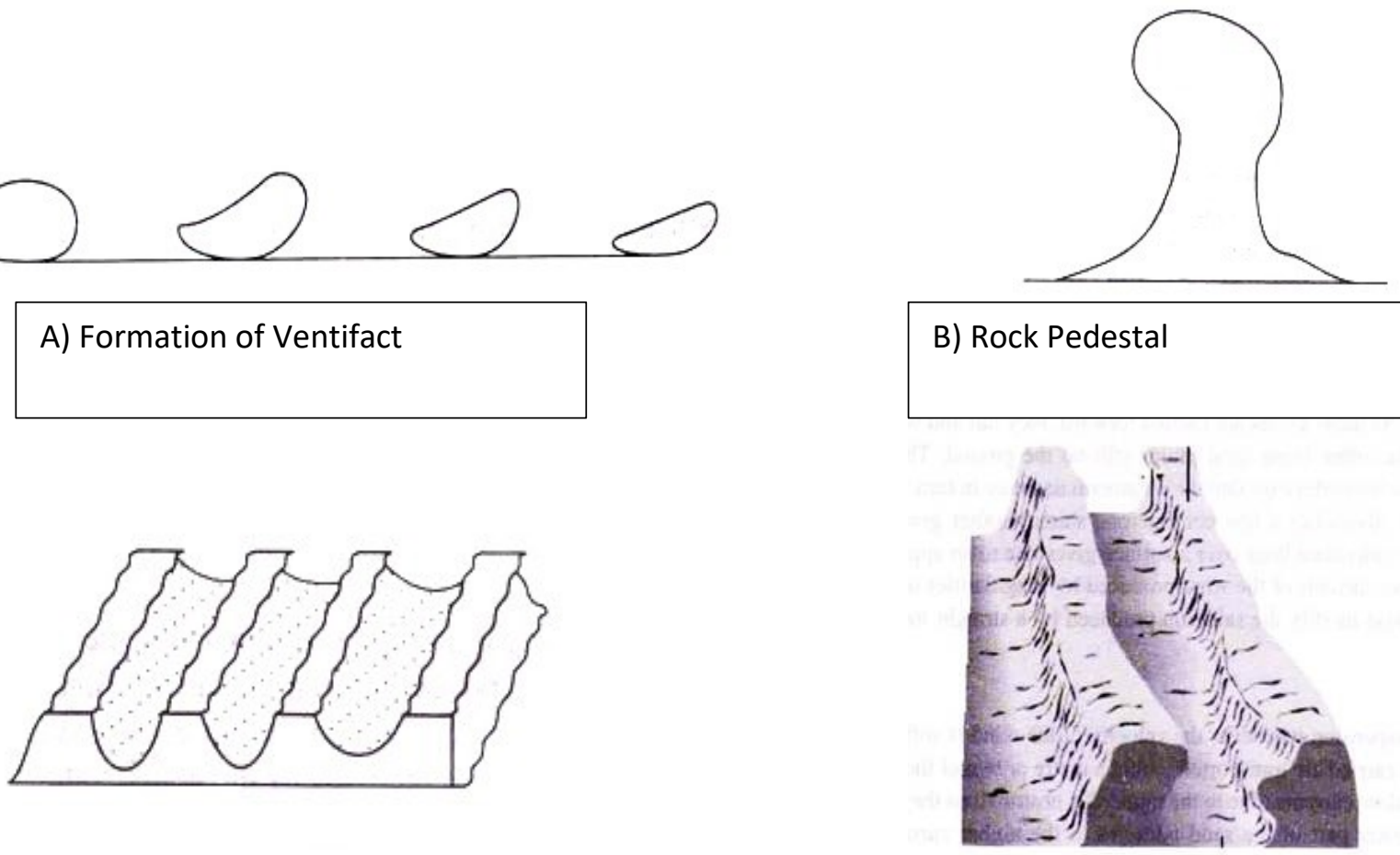

C) Zeugen

D) Yardangs

Figure 3.10: Examples of ventifact (A), rock pedestal (B), zeugen (C) and yardangs (D). Source: http://www.yourarticlelibrary.com/geology/wind-erosion/6-main-features-of-wind-erosion-geology/91192

Yardangs are formed in environments that have strong uni-directional winds that cut down low lying areas into parallel ridges which gradually erode into individual hills. They are commonly created from softer rock types such as siltstone, sandstone, shale and limestone but are also observed in schist and gneiss (Goudie, 2007). Given the uncertainties in the topography measurements, it is not possible to assess the height of the observed yarding on Venus. However, given the similarity in appearance and style of dunes, it can be inferred that their geometry is similar Earth. Yardangs on Earth (and other terrestrial planets), are divided into three major categories: mega-yardangs (several kilometers long 
and hundreds of meters high), meso-yardangs (few meters high and 10 to 15 meters long) and micro-yardangs (few centimeters high) (Dong et al., 2016).

Zuegens are similar to yardangs but can be distinguished from wind streaks by having well-defined boundaries and not originating (i.e., being situated downwind) from topographic features. Although yardangs have been reported in the post-tessera volcanic regions, the important question is whether such wind erosional features could explain the topographic variations in tesserae. In terms of appearance both yardangs and zeugens tend to be parallel and elongated, so these wind erosional features could only explain those patterns where the valleys (and ridges between them) are linear (e.g. Figure 3.7C, 3.8A and 3.8B,). Figures 3.7A, 3.7B, 3.7D, 3.8C, and 3.8D do not exhibit parallel ridges and thus are unlikely to have been shaped by wind.

\subsection{Glacial Erosion}

Glacial features have not previously been observed on Venus and can not occur under current hyper-warm temperatures. However, glaciers would be possible if Venus was previously home to cooler temperatures. As noted in Way et al. (2016) climatic conditions (700 Ma ago) on Venus would be favourable for free water. This would imply that there could be lower temperatures at high elevations at that time or transient sub-zero conditions that would allow for the possibility of snow and ice. As a result, any evidence for processes of glacial erosion should also be considered for tesserae on Venus. 


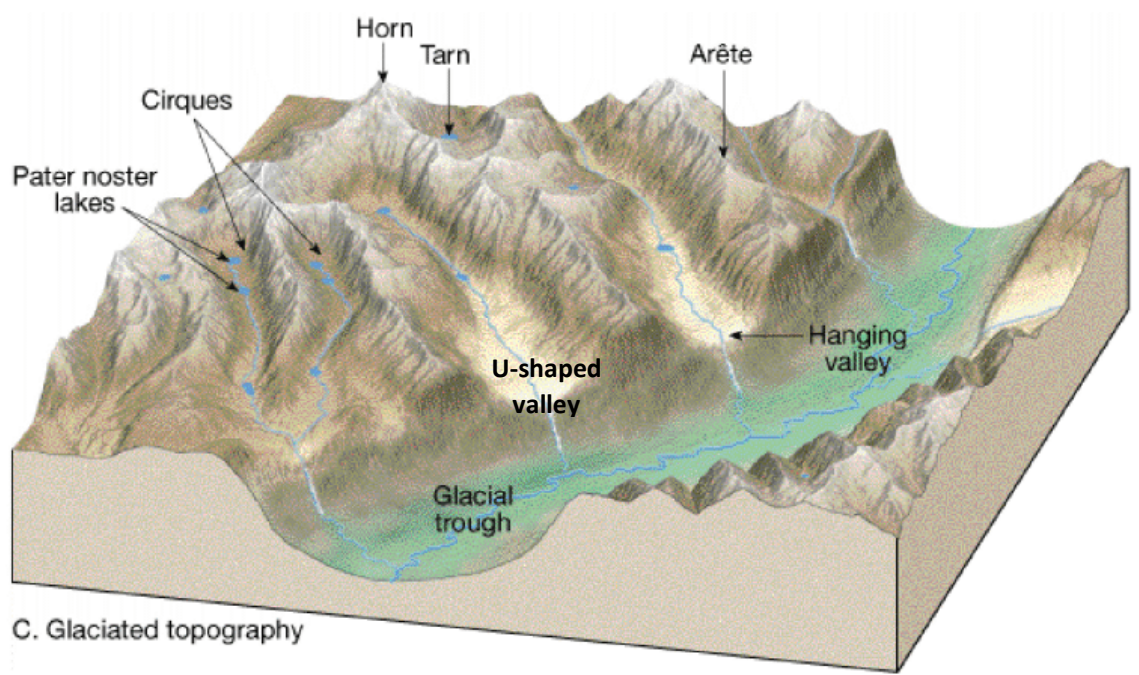

Figure 3.11: Glacial landforms created as a result of erosion. Major landform types include: cirque (starting location of a glacier), arete (narrow ridge crated by two joining cirques), horn (three or more glacially eroded aretes), tarn (mountain lake formed in a cirque dug out by a glacier), pater noster lakes (a glacial lake connected by a single stream or braided stream system), hanging valley (valley cut across by deeper valley or cliff), Ushaped valley (results from glacier moving through valley), ribbon lakes (long, narrow lakes found in glaciated U-shaped valleys) and fjords (U-shaped valley filled with melting glacier water) (Tarbuck and Lutgens, 1998; Bennett and Glasser, 2011).

There are several erosional features that are formed due to glacial processes (Figure 3.11). Unfortunately, the features are impossible to recognize in the Magellan images of Venus given the poor vertical and horizontal resolution in topography. Features such as cirques and hanging valleys will be present in the high standing areas (peaks and ridges), but it is not possible to resolve the fine scale topography which would be essential to reveal a glacial origin in these upland areas. Also, the subsequent lava flooding of the valleys would obscure any recognition of U-shape valleys (diagnostic of glaciers) vs V-shape valleys (more diagnostic of fluvial erosion). Identification of glacial features on Venus will have to await higher resolution data from a future mission. 


\subsection{Implications of Fluvial Erosion Interpretation}

The prospect of fluvial erosion in tesserae provides a new interpretative framework for this important but enigmatic terrain type on Venus; two implications are discussed below.

\subsubsection{Linking stream drainage pattern with underlying geology.}

Terrestrial stream drainage patterns are controlled by rock properties and slopes (Bridge and Demicco, 2008) and thus the type of stream valley network that best fits a particular tessera could be indicative of local geology. As a generalization, radial, parallel and dendritic patterns are formed on slopes underlain by homogenous material. Trellis and rectangular patterns can be caused by dipping sedimentary strata of unequal resistance to erosion, by dipping volcanic flows with differential erosion between the upper and lower portions of a flow, and/or by orthogonal pre-existing fracture patterns. Radial patterns develop on topographic domes or basins composed of homogenous material. More specifically, with respect to the tesserae valley patterns in Figures 3.7 and 3.8, the following geological interpretations can be offered. The pattern in Figure 3.7A (and Figure 3.6) is consistent with a NNE-SSW-trending aulacogen-like structure (a failed arm of a triple junction rift system) that has been smoothed by erosion (removing the trace of any bounding normal faults) with incision along weak orthogonal (NW-SE trending) features (possibly dykes or a tilted section of a sill complex or a volcano-sedimentary sequence). Figure 3.7B is consistent with streams converging on a sedimentary basin with potential outflow to the NW or SE. Figure 3.7C is consistent with an E-W-trending horst and graben rift zone with superimposed erosion. Figure 3.7D is consistent with erosion affecting a geologically complex terrain. Building on the initial insights here, a global study of partially-flooded tesserae at a variety of latitudes 
and altitudes, and their interpretation in terms of stream drainage pattern types could provide global a reconnaissance-level geological interpretation of tesserae.

\subsubsection{Allowing simplified interpretation of lineament patterns in tesserae}

Tesserae are characterized by complex lineament patterns, which can be irregular and/or curvilinear. A fluvial erosion model offers the possibility that such patterns reflect shallowdipping planar layers of sediments or volcanic sequences that have been differentially eroded (Byrne et al., 2019, Byrne et al., 2020; Khawja et al., 2019, Khawja et al., 2020). This aspect is evaluated further in Chapter 4.

\subsection{Conclusion}

Partial lava flooding along the margins of tesserae are used as a local datum to reveal the pattern of local topographic highs (peaks and ridges) versus "valleys". These patterns are considered against the default model in which no erosion was considered and therefore all topography could only be due to primary folds and faults. The complexity of tesserae are more simply explained if primary tectonics processes are combined with erosion.

The role of water, wind, glacial erosion are considered. The scale of wind erosion on Earth would not be sufficient to explain the erosional patterns on Venus. The topographic resolution of Venusian topography is not sufficient to recognize the essential features of glacial erosion (U-shaped valleys, cirques, hanging valleys) on the upland areas. On the other hand, water erosion can produce the appropriate "valley" patterns and thus represents a viable explanation for local topographic variation in tesserae on Venus. 
The following Chapter discusses implications for the interpretation of lineaments sets in tesserae arising from the recognition of erosion. 


\section{Chapter: Influence of Erosion on Tesserae Lineaments}

\subsection{Introduction}

This Chapter addresses interpretations of observed lineament sets in tesserae and includes the additional options that arise from including the possibility of erosion having occurred (Chapter 3). This contrasts with previous studies of tesserae lineament sets that do not consider the possibility of erosion. Topographic profiles that are both parallel and perpendicular to lineament sets are presented in order to document the degree of topographic variation along and across lineament sets. The interpretations discussed herein assume that lineaments are the surface trace of planar tectonic and/or geological features. This study also introduces principal component analysis (PCA) as a methodology to calculate the orientation of planar surfaces which due to differential erosion can exhibit curved surface traces (lineaments) if the planar feature is non vertical. 


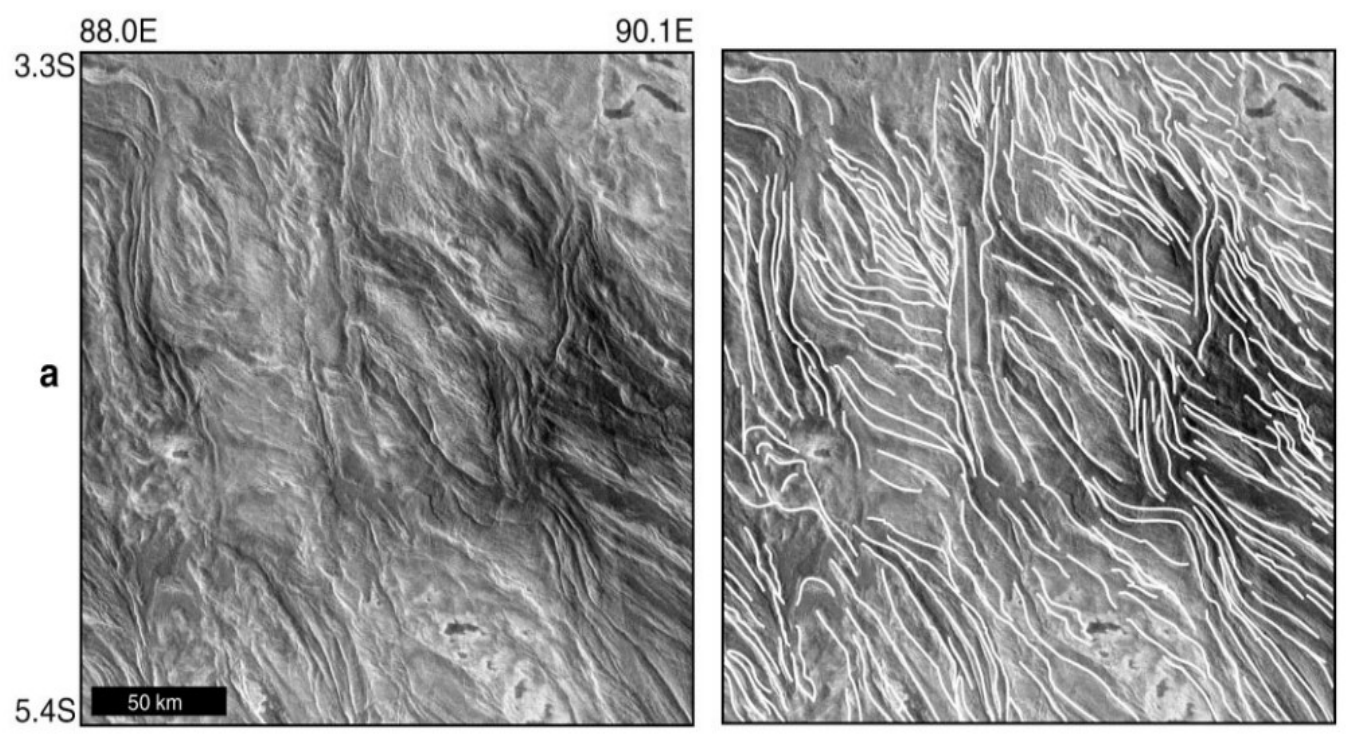

Figure 4.1: Lineaments interpreted as fold crests in eastern Ovda Regio (Ghent and Hansen, 1999). Original SAR image (top left) and annotated version (top right).

\subsubsection{Lineaments on Tesserae}

Lineament sets on tesserae (imaged by SAR) are generally interpreted in the current literature as representing tectonic structures (Figures 4.1 and 4.2) of various types including fractures, grabens, open tensile fractures, 'ribbons' and narrow fold crests. Gilmore et al. (1998) debated whether specific lineaments within tessera were grabens (bounded by faults dipping $\sim 60^{\circ}$ ) or open tensile fractures (dipping $\sim 90^{\circ}$ ). The term "ribbon" has been applied to symmetrical, steep-sided, graben-like structures generated by extensional forces (Hansen, 2018; Gilmore and Head, 2018). However, it is difficult to differentiate between ribbons and grabens given current resolution of SAR images. Hanmer (2020) proposed that the ribbons seen on tesserae represent grabens above dykes, similar to the interpretation for many grabens found in younger volcanic areas (e.g. Grosfils and Head, 1994). Some lineaments have also been interpreted as fold crests (Figure 4.1) (e.g. Hansen, 1997) which can be wide, straight or curved. Hansen (1997) notes that folds are radar bright along one side, have a 
gradual brightness transition across them, and can be distinguished from fractures which are typically marked by a sharp zone of radar brightness and overall high contrast with surrounding areas.

If tesserae experienced erosion (Chapter 3), then additional interpretations are possible. For instance, lineaments can represent the surface trace of primary igneous or sedimentary layering that has been tilted and eroded. In particular, curved lineament sets can represent planar feature layers eroded differentially. Figure 4.3 illustrates the broad range of lineament interpretations in tesserae. 

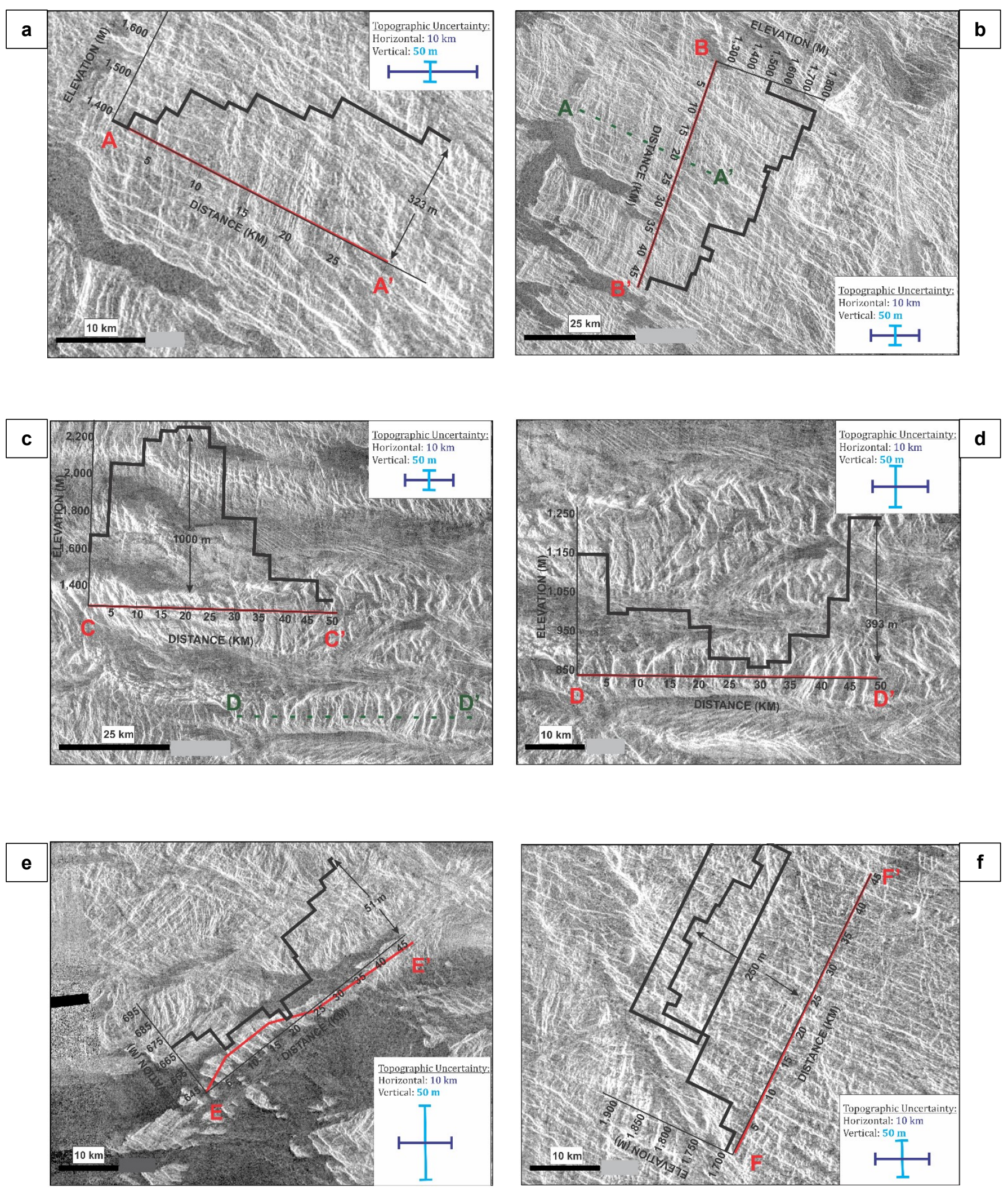

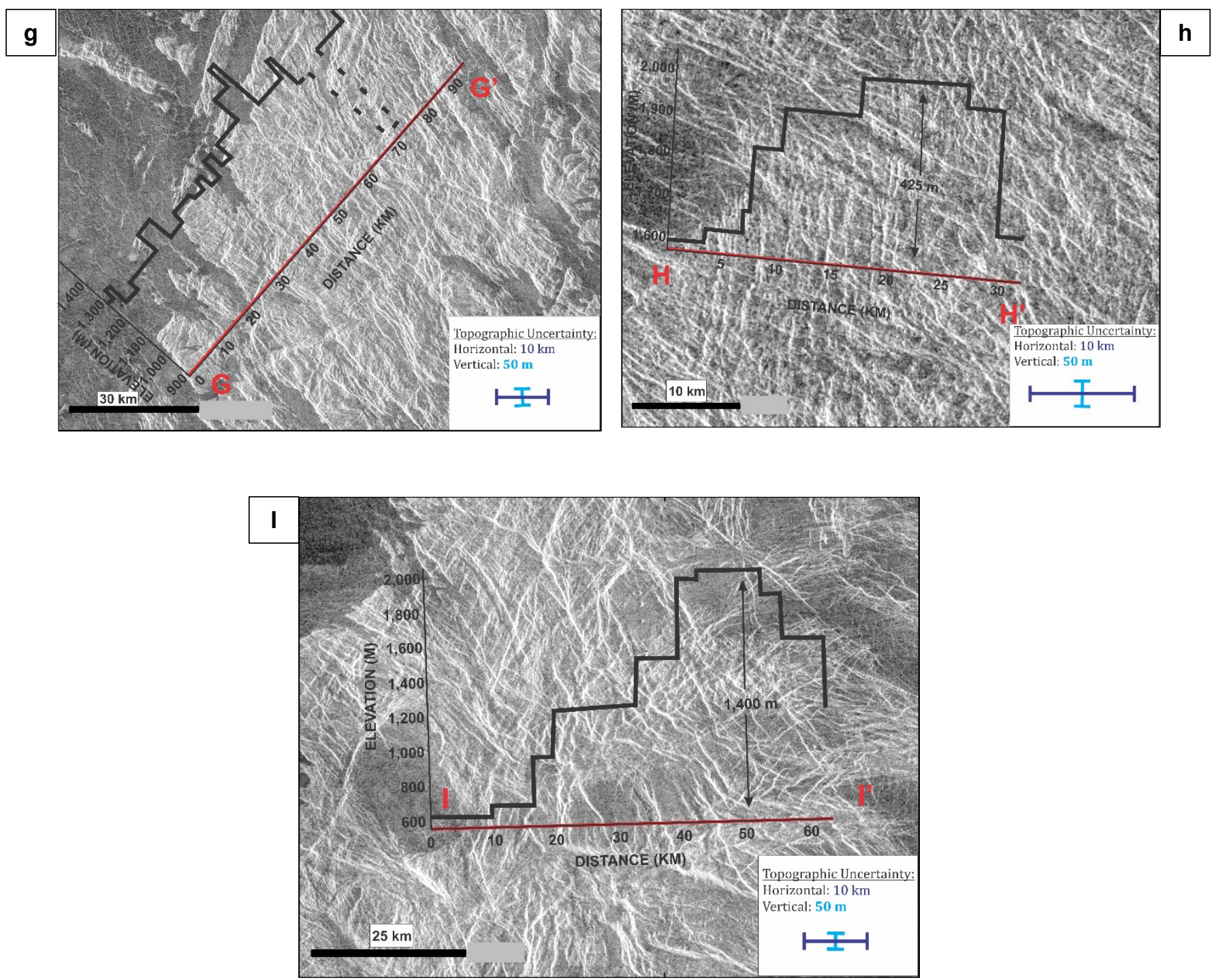

Figure 4.2: Portions of Salus Tessera (Figure 2.2) with superimposed topographic profiles. Minimum topographic uncertainties are provided for each profile based on a horizontal topographic footprint of $10 \mathrm{~km}$ and a vertical uncertainty of $50 \mathrm{~m}$. Topographic profile data are extracted from JMARS. Profile location are shown in Figure 4.2.

Table 4.1: Average slope calculated for each profile in Figure 4.2

\begin{tabular}{|c|c|c|c|c|c|}
\hline PROFILE & Point 1 (distance, km) & Point 1 (elevation, m) & Point 2 (distance, km) & Point 2 (elevation, m) & Slope (degrees) \\
\hline a & 5 & 1460 & 30 & 1650 & $\quad 0.44$ \\
\hline$b$ & 5 & 1800 & 30 & 1450 & 0.80 \\
\hline c & 5 & 2050 & 35 & 1500 & 1.05 \\
\hline$d$ & 5 & 1150 & 40 & 950 & 0.33 \\
\hline e & 5 & 670 & 40 & 685 & 0.02 \\
\hline$f$ & 15 & 1900 & 40 & 1850 & 0.11 \\
\hline g & 10 & 1290 & 60 & 1300 & 0.01 \\
\hline h & 5 & 1620 & 25 & 2000 & 1.09 \\
\hline i & 10 & 650 & 50 & 2000 & 1.93 \\
\hline
\end{tabular}




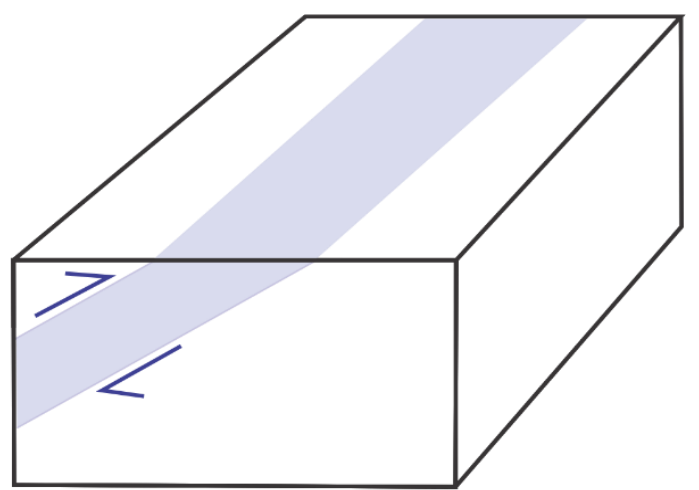

\section{b}

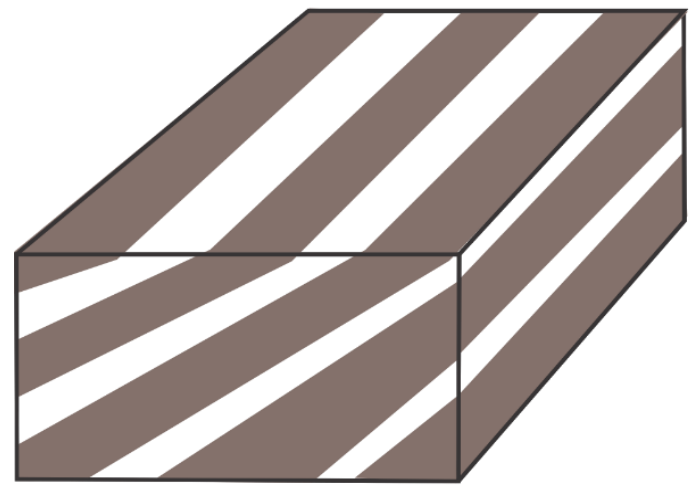

C

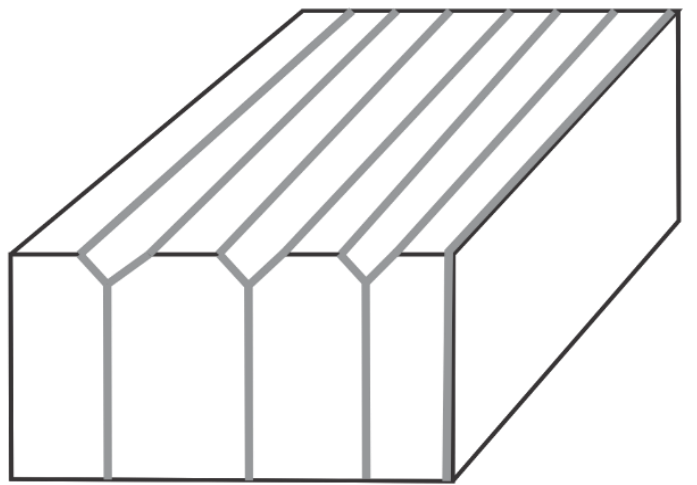

d

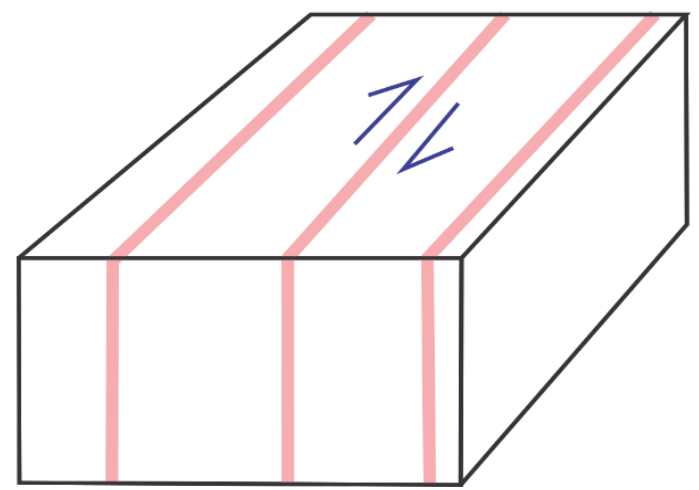

Figure 4.3: Block diagrams representing the surface trace (lineaments) corresponding to different types of sub-surface tectonic and geological features: a) a thrust fault, b) sedimentary bedding or volcanic flows, c) grabens and d) strike-slip faults. 
Basic geological features could be recognized as lineaments in tesserae in several ways. Thrust faults could appear as widely spaced lineaments that have shallow to steep dips, which would reflect the listric geometry of such faults (Figure 4.3a). Sedimentary and volcanic sequences would typically appear as narrow spaced lineaments that are subhorizontal or tilted if there is some deformation (Figure 4.3b). On the other hand, subvertical geological features can range from narrow to widely spaced lineaments, and can include normal faults, strike-slip faults (Figure 4.3d), dykes and their overlying graben (Figure 4.3c). Any subsequent block tilting or folding would change the dip of planar features. 

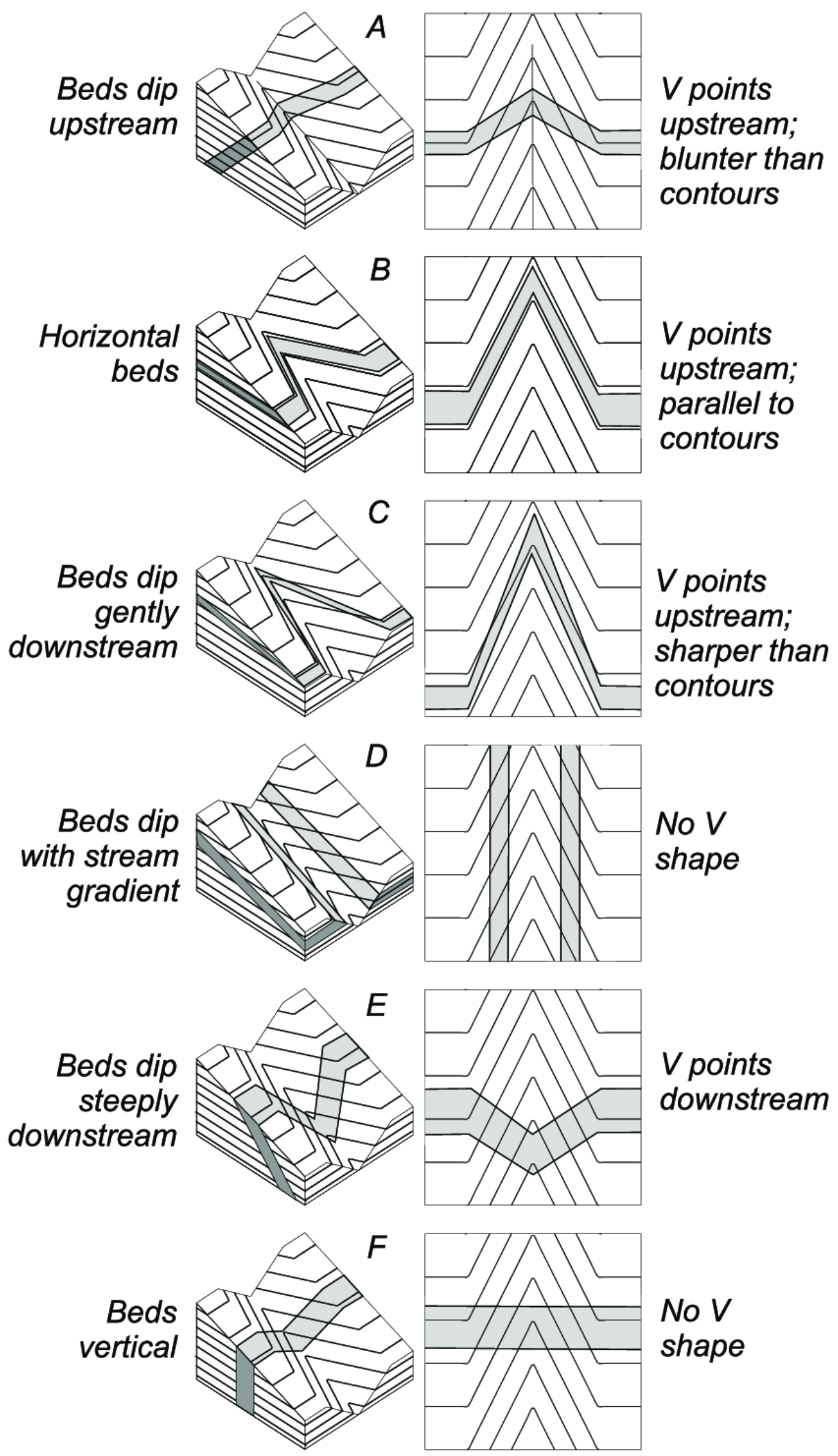

Figure 4.4: Illustration of the Rule of V's (Lisle, 2003). 
The possibility of erosion (Chapter 3) can provide constraints on the dip of layers. Differential erosion causes surface lineaments of planar features to curve. For instance, according to the 'Rule of V's' the presence of erosional valleys causes apparent curving of surface lineament traces up- or down-stream depending on the dip of the planar features (Figure 4.4). On the other hand, straight lineaments may represent vertical planar surfaces across any topography. Straight lineaments can also represent planar surfaces of any dip as long as the strike of the plane is along a line of constant elevation. For lineaments that represent fold structures, the effect of erosion is shown in Figure 4.5. If there is no erosion, the fold crest is represented by simple straight lineaments. However, erosion would progressively remove the fold crest, and lead to a pair of lineaments marking the boundaries between folded units (Figure 4.5).
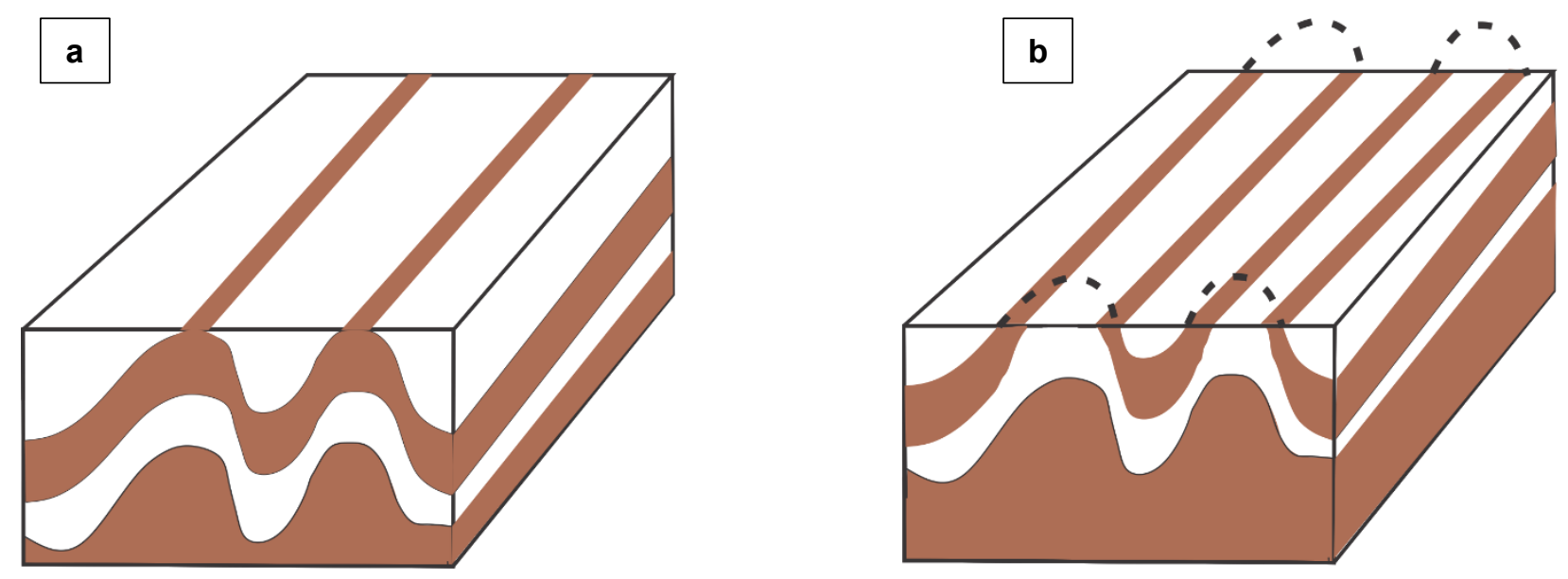

Figure 4.5: Lineament expressions due to folding (a) and erosion (b).

\subsubsection{Topographic Profiles}

Topographic profiles were generated across portions of Salus Tessera (Figure 4.2). These were aligned parallel and/or perpendicular to dominant lineament trends. There were 
several goals of this exercise: A) To assess the topographic variation; B) Identify changes in topography that could be associated with obvious features in the SAR image (e.g. faults); and C) Provide constraints on layer spacing based on lineament spacing and topography.

A) The magnitude of topographic variation differs throughout the various profiles (Figure $4.2 \mathrm{a}-\mathrm{i})$. Profiles $\mathrm{c}$ and $\mathrm{i}$ vary in topography significantly (1000 $\mathrm{m}$ and greater), whereas profiles $f$ and $g$ have very little variation (less than $100 \mathrm{~m}$ ). All the other profiles (a,b,d,e and h) exhibit intermediate variation in topography. In most cases, the slope is less than 2 degrees, with profiles, $\mathrm{c}, \mathrm{h}$ and $\mathrm{i}$ exhibiting the steepest slopes (Table 4.1).

B) The profiles were further analyzed to identify sudden changes in topography. These changes were attributed to geological features such as faults, or to topographic artefacts (appearing as topographic 'holes') in the dataset (Herrick 2012). An example of a meaningless topographic artefact is shown by the dotted line in profile $f$. In selecting the profiles, these artefacts are avoided where possible by examining the topography layer in JMARS. In all other cases, topographic variation is meaningful. For example, in profile $b$, there is a sharp down-drop of $200 \mathrm{~m}$ at the $30 \mathrm{~km}$ mark, that coincides with the southeastward extrapolated extent of a lava flooded valley, suggesting a fault.

C) Two profiles ( $g$ and $i$ ) that are taken perpendicular to dominant lineament sets are used to estimate layer spacing. Profile g shows a relatively low variation in topography across a set of lineaments. Over the distance of $65 \mathrm{~km}$, there are approximately 13 lineaments present. On average that would allow for lineament spacing of $5 \mathrm{~km}$, based on the assumption that these lineaments represent vertical layers. On the other hand, if these lineaments represent subhorizontal layers, the spacing between them would be almost negligible. Profile i shows a high variation in topography (greater than $100 \mathrm{~m}$ ). Over the distance of 50 
$\mathrm{km}$, there are approximately 8 lineaments present. That would allow for lineament spacing of $7 \mathrm{~km}$, assuming these lineaments represent vertical layers. If they were horizontal layers, the lineament spacing would be $0.2 \mathrm{~km}$.

\subsection{Calculating Dip of Planar Surfaces}

\subsubsection{Dip}

Strike and dip measurements are simple yet important calculations for structural and stratigraphic analysis in geological sciences. The dip of a planar geological feature is defined as the amount this layer is tilted from the horizontal. The strike value is the compass direction along the horizontal line of a planar geological feature. Generally, these measurements are done in the field directly at the outcrop of a geological feature. In planetary sciences, this approach is not possible for obvious reasons. Therefore, the only way to get information about the spatial orientation of planar geologic features on Venus is through the use of remote sensing data. This study uses JMARS to obtain the horizontal position ( $\mathrm{x}$ and y axis coordinates, quoted as "North" and "East" in equation 1) and its elevation (z coordinate, quoted as "Elevation" in equation 1) along individual lineaments and uses XLSTAT for mathematical calculations of the orientation of the best fit associated planar feature.

\subsubsection{Methodology for PCA (Principal Component Analysis)}

Principal component analysis (PCA) is a widely used technique for reducing the dimensionality of data sets (Kirschvink, 1980; Jolliffe and Cadima, 2016; Lever et al., 2017; Hopkins and John, 2018; Frank and Smith, 2019;). PCA is a linear transformation of the 
orthogonal coordinate axes to a new reference frame (new coordinate axes) that corresponds to the inherent geometry of the data set via least squares fit. Each axis in the new system is associated with a measure of its variance. Two of the axes are positioned to represent the maximum and minimum direction of variance (F1, F3), while the other is intermediate (F2). PCA yields eigenvectors (F1, F2 and F3) (Figure 4.6) which indicate the direction of the new axes. Eigenvalues $\left(\lambda_{F 1}, \lambda_{F 2}, \lambda_{F 3}\right)$ associated which each eigenvector represent variance $\left(\sigma^{2}\right)$ of data along the new axes. In this study, F1 and F2 are in the plane of the layer; F3 is perpendicular to the plane (Figure 4.6) and is used to calculate dip using equation (1). PCA was calculated using XLSTAT (Chapter 2).

(1) $D I P=\arctan \left(\frac{\sqrt{\text { North }^{2}+\text { East }^{2}}}{\text { Elevation }}\right)$

Where North, East and Elevation are components of the F3 eigenvector. 


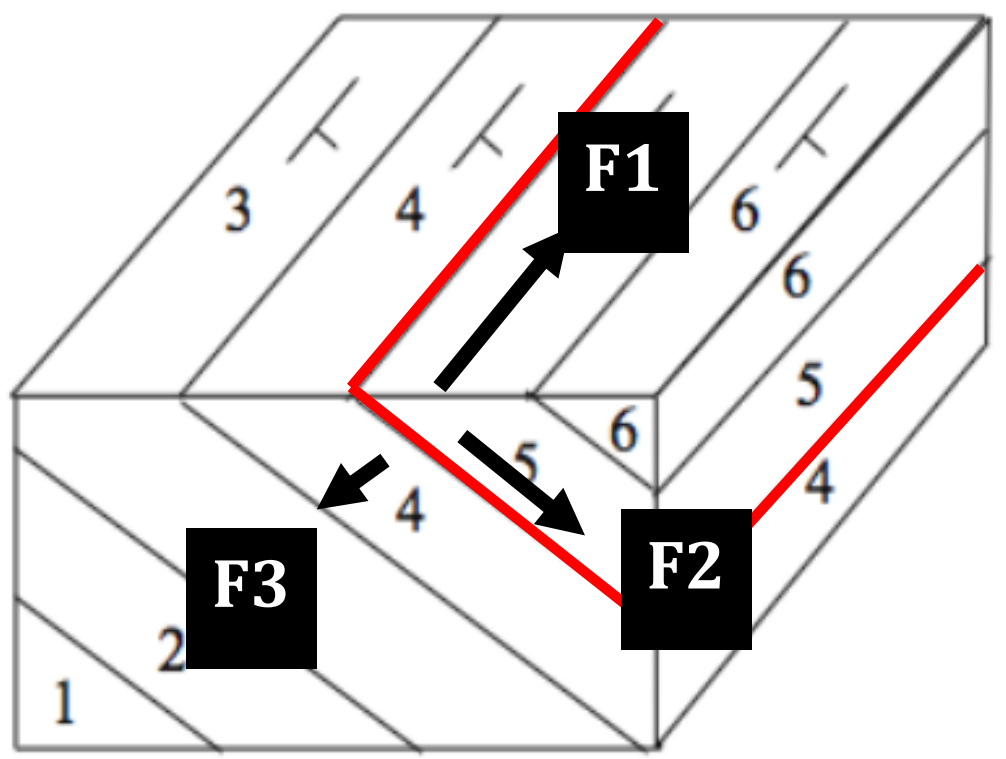

Figure 4.6: eigenvectors associated with plane; F1 and F2 are in the plane of the layer and F3 is perpendicular. The uncertainty in the best fit plane is based on Kirschvink (1980) and was originally designed for the analysis of paleomagnetic demagnetization data. The uncertainty in such a best-fit plane was determined from the variance. For the best fit plane (and line) Kirschvink (1980) considered a rectangular box with dimensions based on the variance $\sigma_{\max }, \sigma_{\text {int }}, \sigma_{\min }$, and determined the maximum angular uncertainty (which he termed the Maximum Angular Deviation (MAD)) as given by equations 2 and 3 for MAD plane and MAD line, respectively.

(2) $\mathrm{MAD}_{\text {plane }}=\arctan \left(\sqrt{\frac{\lambda_{F 3}}{\lambda_{F 2}}+\frac{\lambda_{F 3}}{\lambda_{F 1}}}\right)$

(3) $\mathrm{MAD}_{\text {line }}=\arctan \left(\sqrt{\frac{\lambda_{\text {int }}+\lambda_{\text {min }}}{\lambda_{\max }}}\right)$ 
4.2.3 Methodology for Calculating Dip

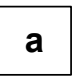

b

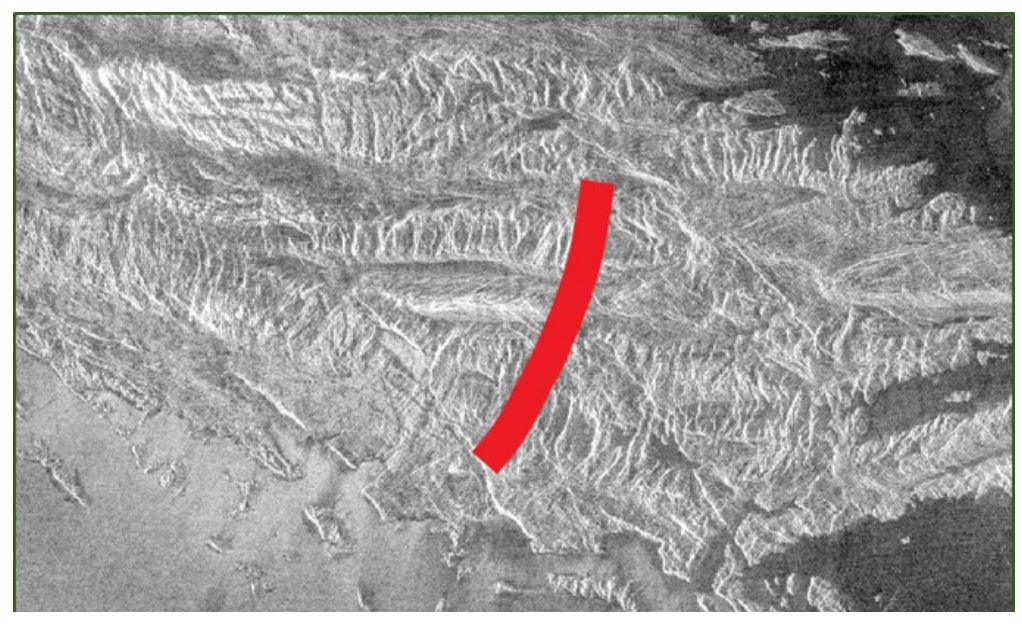

\begin{tabular}{|c|c|c|}
\hline North $(m)$ & East $(m)$ & Elevation $(m)$ \\
\hline 9390 & 16191 & 864 \\
\hline 22192 & 22870 & 1085 \\
\hline 30429 & 24428 & 1148 \\
\hline 34994 & 25096 & 1039 \\
\hline 42675 & 26989 & 1167 \\
\hline 48241 & 27434 & 1357 \\
\hline 54363 & 27434 & 1218 \\
\hline
\end{tabular}

c EIGENVALUES

\begin{tabular}{llll}
\hline & F1 & F2 & F3 \\
\hline Eigenvalue & 2.785 & 0.155 & 0.060
\end{tabular}

d EIGENVECTORS

\begin{tabular}{lcr|r}
\hline & F1 & F2 & \multicolumn{1}{c}{ F3 } \\
\hline North (m) & 0.580 & -0.502 & -0.642 \\
East $(\mathrm{m})$ & 0.585 & -0.292 & 0.757 \\
Elevation & 0.567 & 0.814 & -0.125 \\
\hline
\end{tabular}


e CALCULATING DiP

$$
\begin{aligned}
& D I P=T A N^{-1}\left(\frac{\sqrt{-0.642^{2}+0.757^{2}}}{-0.125}\right) \\
& \text { Dip }=83^{\circ}
\end{aligned}
$$

$$
\begin{aligned}
& M A D=\arctan \left(\sqrt{\frac{0.06}{0.155}+\frac{0.06}{2.785}}\right) \\
& M A D=33^{\circ}
\end{aligned}
$$

Figure 4.7: Example of calculation of best fit dip and uncertainty from lineament data. a: example of lineament (red line) chosen on Salus Tessera. b: xyz points along associated lineament (red line). c: eigenvalues calculated using PCA. d: eigenvectors calculated using PCA. e: calculated dip using equation 1 . f: maximum angular deviation (MAD) calculated using equation 2.

The following steps are required to estimate dip of planes associated with observed lineaments on Salus Tessera: A) Identify lineaments which exhibit a change of elevation along the lineament (Figure 4.7a). B) Take measurements along the chosen lineament recording both horizontal position and elevation (Figure 4.7b). A minimum lineament length of $20 \mathrm{~km}$ is suggested due to the $10-20 \mathrm{~km}$ horizontal footprint for the elevation measurement. A minimum elevation change of $200 \mathrm{~m}$ is suggested due to the $50-100 \mathrm{~m}$ vertical uncertainty. Areas with topographic artefacts are avoided and chosen lineaments are assumed to represent the surface trace of planar features. C) The data points for each lineament are input into Microsoft Excel. The dip and MAD are then calculated using equations 1 and 2, respectively. Lastly, the calculated dip of the inferred planar feature is used to constrain the interpretation of the lineament set. 
4.3 Results

4.3.1 Calculated examples for Salus Tessera

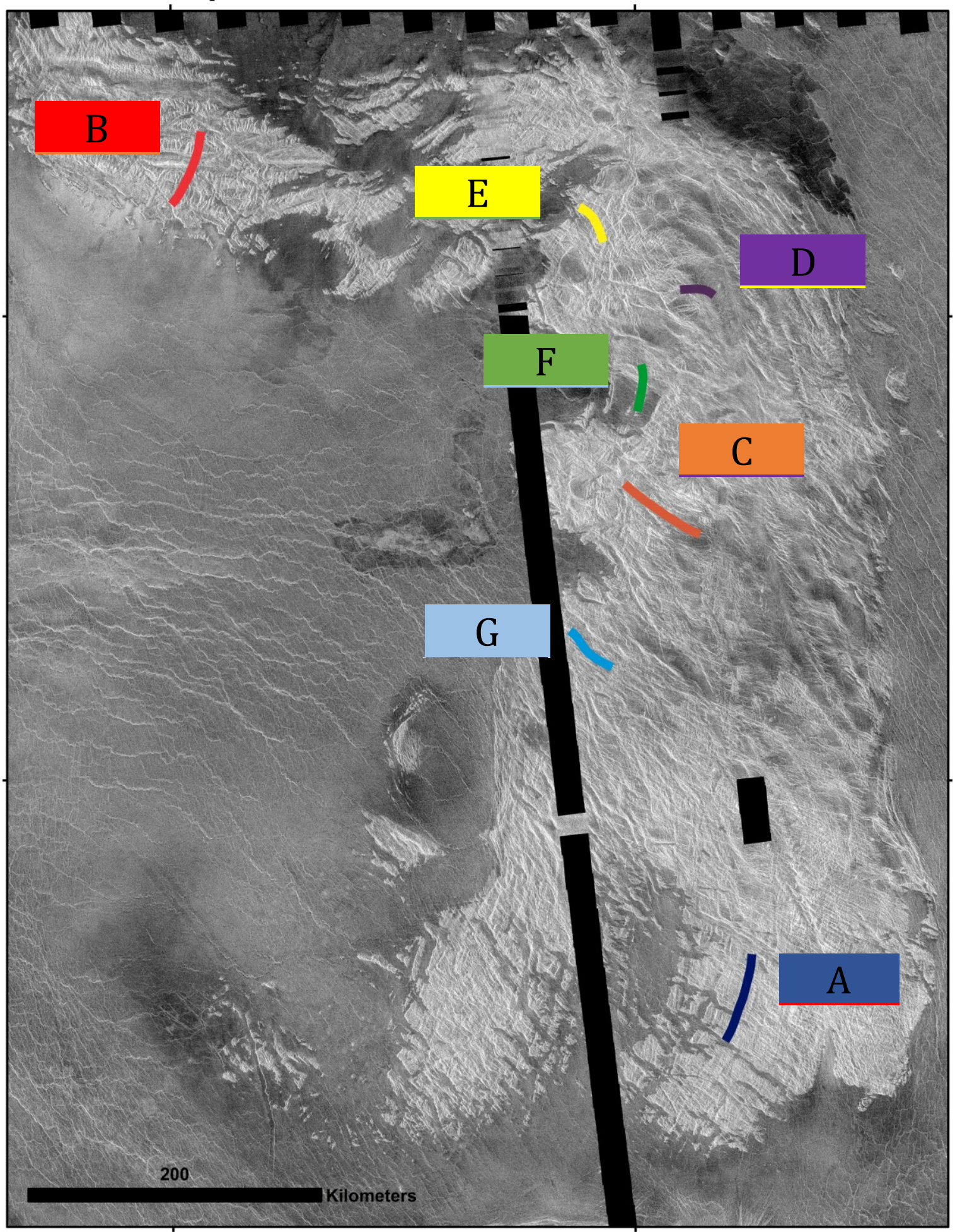




\begin{tabular}{|l|r|r|r|}
\hline & LINEAMENT & DIP $\left(^{\circ}\right)$ & MAD $\left.^{\circ}{ }^{\circ}\right)$ \\
\hline A & 86 & 4 \\
\hline B & 83 & 33 \\
\hline C & 87 & 13 \\
\hline D & 65 & 18 \\
\hline E & 82 & 25 \\
\hline F & 46 & 14 \\
\hline G & 85 & 5 \\
\hline
\end{tabular}

Figure 4.8: Lineament sets chosen for analysis on Salus Tessera (top) and their associated dip and MAD values (bottom). The dip direction for each lineament is towards the concave side.

The dip and MAD are calculated using PCA for 7 profiles (Figure 4.8). Calculations for each lineament can be found in Appendix A. Of those lineaments, 5 (profiles A-C, E and G) appear to be associated with subvertical planes and 2 (profiles D and F) are associated with planes of intermediate dip (Figure 4.9).

\section{PROFILE D:}
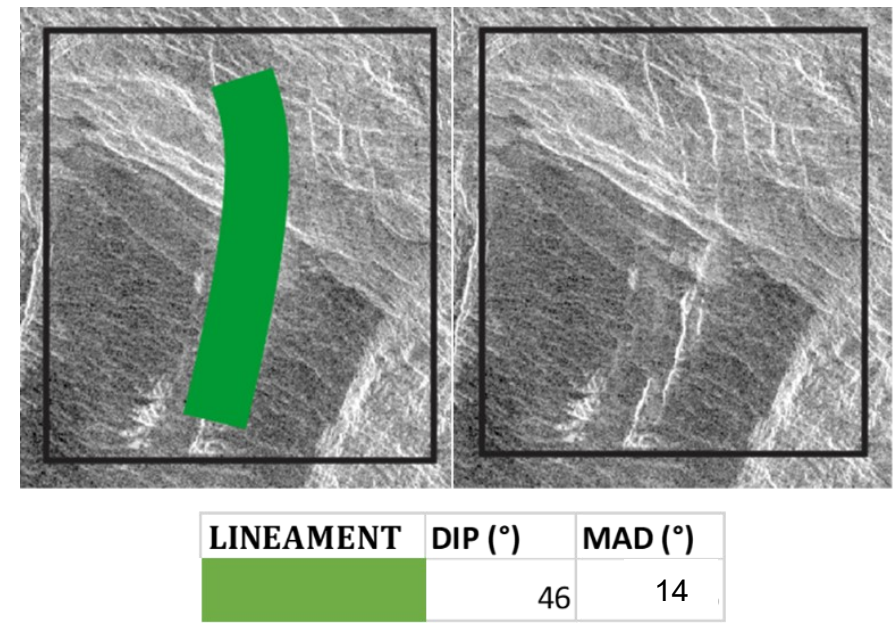

\section{PROFILE F:}
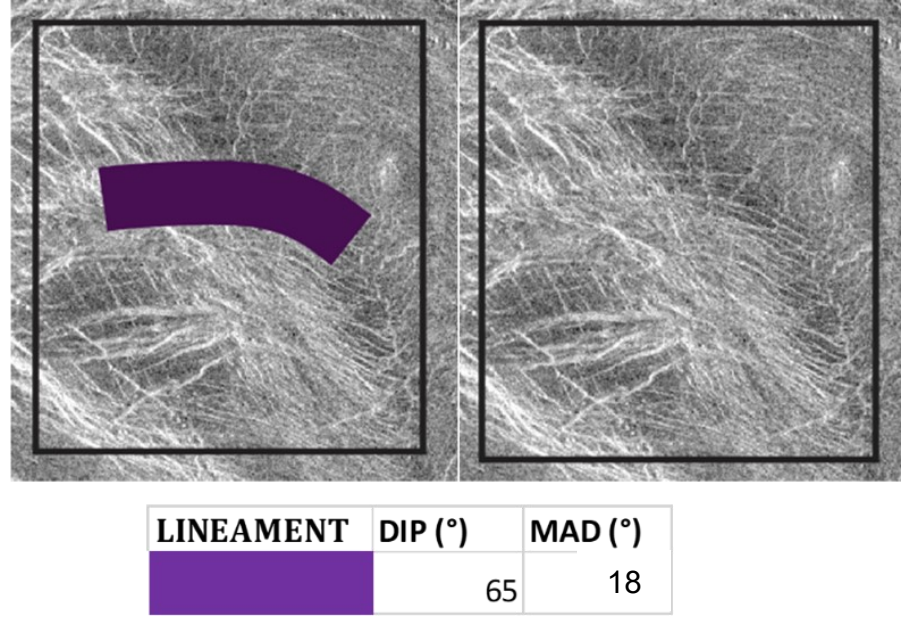

Figure 4.9: Close-up look at two lineaments that are associated with intermediate dips 


\subsubsection{Uncertainties Associated with PCA Calculations}

Given a vertical uncertainty of 50-100 m in Venusian topographic data, all topographic variations that exceed that value can be considered 'real', except in the vicinity of topographic artefacts in the dataset. On the other hand, because there is a horizontal 'footprint' of 10-20 km, there is uncertainty in which specific feature in the Magellan image (75-100 m per pixel resolution) can be linked with a topographic change. The topographic value is essentially averaging over that footprint size. As a result, the topographic data may be smoothed over these areas and the true topographic variation is likely to be more extreme. These large uncertainties in the topographic data imply larger uncertainties in the dips calculated from PCA. This technique would be better applied in areas of the higher resolution topographic data created by Herrick (2012), which are not available for Salus Tessera.

\subsubsection{Role of erosion}

If the lineaments are only a result of tectonic features (extensional fractures, grabens, strike slip faults) then differential erosion is not required, which is the implicit assumption of most previous studies. However, the possibility of erosion in tesserae (Chapter 3) allows additional interpretations for lineaments. This is especially true for intermediate to shallow dipping planar features (as calculated using the methodology above) which can be sills, volcanic or sedimentary units exposed by differential erosion.

\subsection{Conclusion}

Tesserae are known to exhibit a variety of lineaments that can be linear or curved, and closely or widely spaced. It can be assumed that these represent the surface trace of planar 
geological features. Purely tectonic interpretations of associated planar features include faults, grabens and fold crests. However, given the possibility of tesserae erosion, then additional types of interpretations are possible, such as layered geological units (sedimentary or volcanic) exposed by differential erosion. A key parameter in interpreting the nature of these planar units is to assess their dip. A methodology is developed using PCA to calculate dips and their uncertainties and applied to 7 lineaments in Salus tessera. 


\section{Chapter: Summary and Conclusions}

\subsection{Summary}

Tesserae are highly deformed terrains and are generally located within crustal plateaus on Venus. Tesserae encompass $8 \%$ of the Venusian surface and are dominantly located within equatorial and northern latitudes. They are characterized by high radar backscatter and complex deformation patterns including multiple sets of intersecting lineaments. The processes by which tesserae are formed have not been well understood and multiple models have been put forth in attempts to explain their origin and formation.

An impediment to their full understanding is the unquestioned implicit assumption in the literature that tesserae did not experience erosion. An absence of erosion is clear for the stratigraphically younger basaltic plains and edifice magmatism and is consistent with the current atmospheric temperatures of $450^{\circ} \mathrm{C}$. A recently published climate model allows for the presence of liquid water on ancient Venus, therefore opening up the possibility of identifying erosional features in the stratigraphically oldest units called tesserae.

\subsection{Fluvial Erosion of Tesserae}

Chapter 3 considered the geomorphology of tesserae and explicitly considered the role of fluvial erosion. However, the analytical uncertainty in elevation values (50-100 m vertical and horizontal footprint of 10-20 km) prevents easy identification of valleys in tesserae. Therefore, a proxy approach was developed and used to locate low areas ('valleys') in tesserae. Younger basaltic plains lavas overlap the margins of tesserae and fill any preexisting valleys. Partial flooding by lava flows of the margins in tesserae represents a datum 
that distinguishes valleys from bordering topographic highs (peaks and ridges). These valley patterns were then compared against terrestrial stream systems. A total of 8 examples of valley patterns in tesserae regions were compared with stream drainage patterns on Earth. It was evident that these patterns were morphologically similar to 5 of the 6 recognized stream valley pattern types on Earth. In these cases, the inference was that the valleys were originally formed by stream erosion and these same valleys were infilled by later lava flows. In addition, one area shows a tear drop shaped 'island', consistent with the local inferred direction of stream flow.

The role of wind and glacial erosion were also considered. Yardangs (wind erosion features) can be seen on both Earth and Venus. However, they are characterized with parallel and elongated ridges which could represent only some of the observed valley patterns types. Similarly, essential features of glacial erosion (U-shaped valleys, cirques, hanging valleys etc...) were also not identified on tesserae due to insufficient topographic resolution. As a result, the role of glacial erosion cannot be assessed with the available data.

The recognition of fluvial patterns (Chapter 3 ) in tesserae is a paradigm shift and has significant implications. One of the implications is developed in Chapter 4 (summarized below in section 5.3) and others are mentioned in the Future Work section (section 5.4).

\subsection{Interpretation of Lineament Sets in Tesserae}

Chapter 4 considers the origin of the multiple sets of intersecting lineaments that characterize tesserae. The previous interpretation of tesserae lineaments was based on the implicit assumption that tesserae did not exhibit erosion. In the absence of erosion, lineaments could only represent the surface expression of features such as fold crests, faults 
and grabens. In Chapter 4, tesserae lineaments were assessed from the viewpoint that erosion could have occurred. This allowed additional types of lineament interpretations, namely as the surface trace (exposed by erosion) of the edges of a set of sills, volcanic flows or sedimentary formations. To distinguish between these different interpretations requires insight into the dip of planar features associated with lineament sets. Steeply dipping features could represent faults and grabens while shallowly dipping features could represent sills, volcanics and sedimentary formations. Features of intermediate dips could represent listric faults, tectonically tilted sequences of sills, volcanics and sedimentary formations. Chapter 4 develops a methodology for determining the dip of planar surfaces from surface lineaments.

Principal Component Analysis (PCA) was applied to traces of curved lineaments which varied in elevation. For each analysis, a series of xyz coordinates were obtained ( $\mathrm{x}$ and $\mathrm{y}$ from the Magellan SAR images and $\mathrm{z}$ from the topographic data) and the dip for its associated plane was then calculated. Furthermore, an equation used to calculate Maximum Angular Deviation (MAD), a measure of uncertainty, was adapted from the paleomagnetic literature. PCA/MAD analysis was applied to 7 lineament traces from various regions of a small tesserae called Salus Tessera. It was found that majority of the curving lineaments represented subvertical planar features, although two have intermediate dips of 46 and 65 degrees. 5.4 Recommendations for Future Work

The recognition of erosion in tesserae (Chapter 3 ) is a paradigm shift and has numerous implications. As discussed above (Chapter 4 and section 5.3) this allows for the potential recognition of volcanic flows, sedimentary formations or intrusive sills through differential 
erosion that exposes the stratigraphy as lineament sets. Additional implications discussed below represent important avenues of future research that will build on the results of this thesis.

As discussed in other Chapters, many researchers have attempted to map geological domains within tesserae and to develop a geological history, typically implicitly assuming no erosion has occurred. In the absence of erosion, all the structures and features observed at the surface must represent primary features that were always at the surface since they were formed. However, if tesserae did experience erosion, then it is possible that different domains may represent rocks uplifted and eroded from different crustal depths. The new erosion paradigm introduced in this thesis therefore allows a much richer array of geological and tectonic interpretations of tesserae that was possible when no erosion was considered.

In this thesis, 8 regions of partially flooded tesserae were mapped and compared with terrestrial stream patterns. As noted in Chapter 3 the type of inferred stream valley pattern is reflective of the type of geology and tectonics. A key step going forward is expanding the mapping of stream valley patterns to tesserae from all regions of Venus, in order to provide reconnaissance-level understanding of global tesserae geology and tectonics.

As a result of erosion, tesserae would record a much greater period of Venusian history than presently thought. The age of Venusian features is determined by impacting crater counting and the age of tesserae is comparable to the age of the younger plains flows. However, if tesserae have experienced erosion then meteorite impact craters would only start being preserved when the global warming event occurred and the water cycle was shut off. Therefore, tesserae may preserve a much longer history, potentially billions of years 
prior to the global warming event at $\sim 700 \mathrm{Ma}$. Future mapping and analysis can therefore try to characterize this longer geological history preserved in tesserae. 
Appendix A: Calculations for dip, maximum angular deviation and strike for lineaments on Salus Tessera. See Figure 4.8 for location of analyzed lineaments. The methodology is explained in section 4.3 .

Lineament 1:

\begin{tabular}{|c|c|c|c|c|c|c|c|c|}
\hline North & East & Elevation & North (m) & East (m) & Elevation & North (m) & East (m) & Elevation \\
\hline-4.131 & 48.764 & 1354.5 & -459862.92 & 5428408.48 & 1354.5 & 70137 & 28408 & 1355 \\
\hline-4.172 & 48.762 & 1327 & -464427.04 & 5428185.84 & 1327 & 65573 & 28186 & 1327 \\
\hline-4.203 & 48.752 & 1417 & -467877.96 & 5427072.64 & 1417 & 62122 & 27073 & 1417 \\
\hline-4.248 & 48.74 & 1417 & -472887.36 & 5425736.8 & 1417 & 57113 & 25737 & 1417 \\
\hline-4.291 & 48.738 & 1606.5 & -477674.12 & 5425514.16 & 1606.5 & 52326 & 25514 & 1607 \\
\hline-4.322 & 48.73 & 1606.5 & -481125.04 & 5424623.6 & 1606.5 & 48875 & 24624 & 1607 \\
\hline-4.393 & 48.711 & 1628 & -489028.76 & 5422508.52 & 1628 & 40971 & 22509 & 1628 \\
\hline-4.504 & 48.688 & 1535.5 & -501385.28 & 5419948.16 & 1535.5 & 28615 & 19948 & 1536 \\
\hline-4.609 & 48.662 & 1439 & -513073.88 & 5417053.84 & 1439 & 16926 & 17054 & 1439 \\
\hline-4.66 & 48.633 & 1295.5 & -518751.2 & 5413825.56 & 1295.5 & 11249 & 13826 & 1296 \\
\hline-4.727 & 48.615 & 1369.5 & -526209.64 & 5411821.8 & 1369.5 & 3790 & 11822 & 1370 \\
\hline
\end{tabular}

Eigenvalues:

\begin{tabular}{llll}
\hline & F1 & F2 & F3 \\
\hline Eigenvalue & 2.033 & 0.964 & 0.004
\end{tabular}

Eigenvectors:

\begin{tabular}{llll}
\hline & F1 & F2 & F3 \\
\hline North $(\mathrm{m})$ & 0.689 & -0.186 & -0.701 \\
East $(\mathrm{m})$ & 0.698 & -0.090 & 0.710 \\
Elevation & 0.195 & 0.978 & -0.067 \\
\hline
\end{tabular}

\begin{tabular}{|r|r|r|r|}
\hline CALCULATING DIP & CALCULATING UNCERTAINTY & CALCULATING STRIKE \\
\hline 0.9977 & 0.061 & -1.014035629 \\
\hline-14.797 & 1.730967495 & -0.792366959 \\
\hline-1.503317034 & 0.03538469 & -45.39928256 \\
\hline & 0.035369933 & SOUTH EAST \\
\hline & 2.026547906 & 44.60071744 \\
\hline
\end{tabular}

Lineament 2:

\begin{tabular}{|c|c|c|c|c|c|c|c|c|}
\hline North & East & Elevation & North (m) & East (m) & Elevation & North (m) & East (m) & Elevation (m) \\
\hline 0.803 & 45.061 & 863.5 & 89389.96 & 5016190.52 & 863.5 & 9390 & 16191 & 864 \\
\hline 0.918 & 45.121 & 1084.5 & 102191.76 & 5022869.72 & 1084.5 & 22192 & 22870 & 1085 \\
\hline 0.992 & 45.135 & 1148 & 110429.44 & 5024428.2 & 1148 & 30429 & 24428 & 1148 \\
\hline 1.033 & 45.141 & 1039 & 114993.56 & 5025096.12 & 1039 & 34994 & 25096 & 1039 \\
\hline 1.102 & 45.158 & 1166.5 & 122674.64 & 5026988.56 & 1166.5 & 42675 & 26989 & 1167 \\
\hline 1.152 & 45.162 & 1356.5 & 128240.64 & 5027433.84 & 1356.5 & 48241 & 27434 & 1357 \\
\hline 1.207 & 45.162 & 1218 & 134363.24 & 5027433.84 & 1218 & 54363 & 27434 & 1218 \\
\hline
\end{tabular}


Eigenvalues:

\begin{tabular}{llll}
\hline & F1 & F2 & F3 \\
\hline Eigenvalue & 2.785 & 0.155 & 0.060
\end{tabular}

Eigenvectors:

\begin{tabular}{llll}
\hline & F1 & F2 & F3 \\
\hline North $(\mathrm{m})$ & 0.580 & -0.502 & -0.642 \\
East $(\mathrm{m})$ & 0.585 & -0.292 & 0.757 \\
Elevation & 0.567 & 0.814 & -0.125 \\
\hline
\end{tabular}

\begin{tabular}{|r|r|r|r|}
\hline CALCULATING DIP & CALCULATING UNCERTAINTY & CALCULATING STRIKE \\
\hline 0.9922 & 0.246 & -1.179832493 \\
\hline-7.968 & 1.714503195 & -0.867710072 \\
\hline-1.445943833 & 0.143437683 & -49.71612496 \\
\hline-82.8465 & 0.142465938 & SOUTH EAST \\
\hline & 8.162696944 & 40.28387504 \\
\hline
\end{tabular}

Lineament 3:

\begin{tabular}{|c|c|c|c|c|c|c|c|c|}
\hline North & East & Elevation & North (m) & East (m) & Elevation & North (m) & East (m) & Elevation \\
\hline-1.385 & 48.396 & 1394 & -154178.2 & 5387442.72 & 1394 & 45822 & 387443 & 1394 \\
\hline-1.373 & 48.375 & 1582.5 & -152842.36 & 5385105 & 1582.5 & 47158 & 385105 & 1583 \\
\hline-1.363 & 48.344 & 1838 & -151729.16 & 5381654.08 & 1838 & 48271 & 381654 & 1838 \\
\hline-1.332 & 48.275 & 2067.5 & -148278.24 & 5373973 & 2067.5 & 51722 & 373973 & 2068 \\
\hline-1.283 & 48.189 & 2081 & -142823.56 & 5364399.48 & 2081 & 57176 & 364399 & 2081 \\
\hline-1.242 & 48.127 & 1845 & -138259.44 & 5357497.64 & 1845 & 61741 & 357498 & 1845 \\
\hline-1.201 & 48.076 & 1779 & -133695.32 & 5351820.32 & 1779 & 66305 & 351820 & 1779 \\
\hline-1.148 & 48.018 & 1535.5 & -127795.36 & 5345363.76 & 1535.5 & 72205 & 345364 & 1536 \\
\hline-1.115 & 47.797 & 1580 & -124121.8 & 5320762.04 & 1580 & 75878 & 320762 & 1580 \\
\hline-1.084 & 47.947 & 1547.5 & -120670.88 & 5337460.04 & 1547.5 & 79329 & 337460 & 1548 \\
\hline
\end{tabular}

Eigenvalues:

\begin{tabular}{llll}
\hline & F1 & F2 & F3 \\
\hline Eigenvalue & 2.043 & 0.924 & 0.033
\end{tabular}

Eigenvectors:

\begin{tabular}{llrl}
\hline & F1 & F2 & F3 \\
\hline North $(\mathrm{m})$ & 0.686 & 0.151 & 0.711 \\
East $(\mathrm{m})$ & -0.678 & -0.222 & 0.701 \\
Elevation & -0.264 & 0.963 & 0.050 \\
\hline
\end{tabular}

\begin{tabular}{|r|r|r|r|}
\hline CALCULATING DIP & CALCULATING UNCERTAINTY & CALCULATING STRIKE \\
\hline 0.9988 & 0.181 & 0.985353099 \\
\hline 19.999 & 1.722586374 & 0.778020818 \\
\hline 1.520835886 & 0.104970561 & 44.57730926 \\
\hline 87.1375 & 0.104587539 & NORTH EAST \\
\hline & 5.992424585 & -45.42269074 \\
\hline
\end{tabular}


Lineament 4:

\begin{tabular}{|r|r|r|r|r|r|r|r|r|r|}
\hline North & East & Elevation & North $(\mathbf{m})$ & \multicolumn{1}{|c|}{ East $(\mathbf{m})$} & Elevation & North $(\mathbf{m})$ & East $(\mathbf{m})$ & Elevation \\
\hline 0.1484 & 48.5 & 880 & 16519.888 & 5399020 & 880 & 520 & 399020 & 880 \\
\hline 0.165 & 48.4736 & 810.5 & 18367.8 & 5396081.152 & 810.5 & 2368 & 396081 & 811 \\
\hline 0.1729 & 48.4473 & 810.5 & 19247.228 & 5393153.436 & 810.5 & 3247 & 393153 & 811 \\
\hline 0.1777 & 48.3789 & 831 & 19781.564 & 5385539.148 & 831 & 3782 & 385539 & 831 \\
\hline 0.1777 & 48.374 & 1118 & 19781.564 & 5384993.68 & 1118 & 3782 & 384994 & 1118 \\
\hline 0.1777 & 48.3437 & 1221.5 & 19781.564 & 5381620.684 & 1221.5 & 3782 & 381621 & 1222 \\
\hline 0.1777 & 48.3154 & 1221.5 & 19781.564 & 5378470.328 & 1221.5 & 3782 & 378470 & 1222 \\
\hline
\end{tabular}

Eigenvalues:

\begin{tabular}{llll}
\hline & F1 & F2 & F3 \\
\hline Eigenvalue & 2.429 & 0.524 & 0.048
\end{tabular}

Eigenvectors:

\begin{tabular}{llll}
\hline & F1 & F2 & F3 \\
\hline North $(\mathrm{m})$ & -0.554 & -0.683 & 0.476 \\
East $(\mathrm{m})$ & 0.632 & 0.027 & 0.774 \\
Elevation & -0.542 & 0.729 & 0.417 \\
\hline
\end{tabular}

\begin{tabular}{|r|r|r|r|}
\hline CALCULATING DIP & CALCULATING UNCERTAINTY & CALCULATING STRIKE \\
\hline 0.9087 & 0.218 & 1.627654207 \\
\hline 2.177 & 1.718229292 & 1.019869534 \\
\hline 1.140191777 & 0.127093661 & 58.43421996 \\
\hline 65.3282 & 0.126415911 & NORTH EAST \\
\hline & 7.243098163 & -31.56578004 \\
\hline
\end{tabular}

Lineament 5:

\begin{tabular}{|c|c|c|c|c|c|c|c|c|}
\hline North & East & Elevation & North (m) & East (m) & Elevation & North (m) & East (m) & Elevation \\
\hline 0.7148 & 47.6475 & 806.5 & 79571.536 & 5304119.7 & 806.5 & 19572 & 304120 & 807 \\
\hline 0.7002 & 47.6719 & 828.5 & 77946.264 & 5306835.908 & 828.5 & 17946 & 306836 & 829 \\
\hline 0.6816 & 47.6934 & 712 & 75875.712 & 5309229.288 & 712 & 15876 & 309229 & 712 \\
\hline 0.6631 & 47.7158 & 712 & 73816.292 & 5311722.856 & 712 & 13816 & 311723 & 712 \\
\hline 0.6406 & 47.7314 & 655 & 71311.592 & 5313459.448 & 655 & 11312 & 313459 & 655 \\
\hline 0.6182 & 47.7451 & 615.5 & 68818.024 & 5314984.532 & 615.5 & 8818 & 314985 & 616 \\
\hline
\end{tabular}

Eigenvalues:

\begin{tabular}{llll}
\hline & F1 & F2 & F3 \\
\hline Eigenvalue & 2.917 & 0.069 & 0.014
\end{tabular}

Eigenvectors:

\begin{tabular}{lrrr}
\hline & F1 & F2 & F3 \\
\hline North $(\mathrm{m})$ & -0.581 & -0.281 & 0.763 \\
East $(\mathrm{m})$ & 0.578 & 0.517 & 0.631 \\
Elevation & -0.572 & 0.808 & -0.138 \\
\hline
\end{tabular}




\begin{tabular}{|r|r|r|r|}
\hline CALCULATING DIP & CALCULATING UNCERTAINTY & CALCULATING STRIKE \\
\hline 0.9904 & 0.119 & 0.826449631 \\
\hline-7.176 & 1.727931216 & 0.690661986 \\
\hline-1.432340707 & 0.06909356 & 39.57201685 \\
\hline-82.0671 & 0.068983924 & NORTH EAST \\
\hline & 3.952487724 & -50.42798315 \\
\hline
\end{tabular}

Lineament 6:

\begin{tabular}{|c|c|c|c|c|c|c|c|c|}
\hline North & East & Elevation & North (m) & East (m) & Elevation & North (m) & East (m) & Elevation \\
\hline-0.4951 & 48.0518 & 475 & -55114.532 & 5349126.376 & 475 & 885 & 349126 & 475 \\
\hline-0.4736 & 48.0596 & 475 & -52721.152 & 5349994.672 & 475 & 3279 & 349995 & 475 \\
\hline-0.4434 & 48.0674 & 502 & -49359.288 & 5350862.968 & 502 & 6641 & 350863 & 502 \\
\hline-0.4004 & 48.0693 & 617 & -44572.528 & 5351074.476 & 617 & 11427 & 351074 & 617 \\
\hline-0.376 & 48.0684 & 617 & -41856.32 & 5350974.288 & 617 & 14144 & 350974 & 617 \\
\hline-0.3535 & 48.0659 & 751.5 & -39351.62 & 5350695.988 & 751.5 & 16648 & 350696 & 752 \\
\hline-0.3193 & 48.0566 & 741.5 & -35544.476 & 5349660.712 & 741.5 & 20456 & 349661 & 742 \\
\hline
\end{tabular}

Eigenvalues:

\begin{tabular}{llll}
\hline & F1 & F2 & F3 \\
\hline Eigenvalue & 2.100 & 0.863 & 0.038
\end{tabular}

Eigenvectors:

\begin{tabular}{llrr}
\hline & F1 & F2 & F3 \\
\hline North $(\mathrm{m})$ & 0.673 & -0.186 & -0.716 \\
East $(\mathrm{m})$ & 0.338 & 0.938 & 0.074 \\
Elevation & 0.658 & -0.292 & 0.694 \\
\hline
\end{tabular}

\begin{tabular}{|r|r|r|r|}
\hline CALCULATING DIP & CALCULATING UNCERTAINTY & CALCULATING STRIKE \\
\hline 0.7196 & 0.194 & -0.103069111 \\
\hline 1.036 & 1.72115613 & -0.102706444 \\
\hline 0.803252349 & 0.112693334 & -5.884645744 \\
\hline 46.0230 & 0.112219876 & SOUTH EAST \\
\hline & 6.429725271 & 84.11535426 \\
\hline
\end{tabular}

Lineament 7:

\begin{tabular}{|c|c|c|c|c|c|c|c|c|}
\hline North & East & Elevation & North (m) & East (m) & Elevation & North (m) & East (m) & Elevation \\
\hline-2.1689 & 47.7227 & 1183.5 & -241441.948 & 5312490.964 & 1183.5 & 8558 & 312491 & 1184 \\
\hline-2.1514 & 47.6992 & 1184.5 & -239493.848 & 5309874.944 & 1184.5 & 10506 & 309875 & 1185 \\
\hline-2.1357 & 47.6797 & 1184.5 & -237746.124 & 5307704.204 & 1184.5 & 12254 & 307704 & 1185 \\
\hline-2.1094 & 47.665 & 1229 & -234818.408 & 5306067.8 & 1229 & 15182 & 306068 & 1229 \\
\hline-2.0801 & 47.6445 & 1303 & -231556.732 & 5303785.74 & 1303 & 18443 & 303786 & 1303 \\
\hline-2.0557 & 47.6201 & 1214.5 & -228840.524 & 5301069.532 & 1214.5 & 21159 & 301070 & 1215 \\
\hline-2.043 & 47.5957 & 1214.5 & -227426.76 & 5298353.324 & 1214.5 & 22573 & 298353 & 1215 \\
\hline-2.0303 & 47.5762 & 1171 & -226012.996 & 5296182.584 & 1171 & 23987 & 296183 & 1171 \\
\hline
\end{tabular}


Eigenvalues:

F1

$\begin{array}{llll}\text { Eigenvalue } & 2.042 & 0.953 & 0.005\end{array}$

Eigenvectors:

F1 F2

F3

\begin{tabular}{lrrr} 
& $F 1$ & $F 2$ & \multicolumn{1}{c}{$F$} \\
\hline North $(\mathrm{m})$ & 0.696 & -0.098 & 0.712 \\
East $(\mathrm{m})$ & -0.684 & 0.213 & 0.698 \\
Elevation & 0.221 & 0.972 & -0.081 \\
\hline
\end{tabular}

\begin{tabular}{|r|r|r|r|}
\hline CALCULATING DIP & CALCULATING UNCERTAINTY & CALCULATING STRIKE \\
\hline 0.9967 & 0.068 & 0.980886803 \\
\hline-12.275 & 1.730729925 & 0.775749654 \\
\hline-1.489509021 & 0.039076461 & 44.44718116 \\
\hline-85.3426 & 0.039056589 & NORTH EAST \\
\hline & 2.23777773 & -45.55281884 \\
\hline
\end{tabular}




\section{References}

Barsukov, V. L., Basilevsky, A. T., Burba, G. A., Bobinna, N. N., Kryuchkov, V. P., Kuzmin, R. O., ... \& Shashkina, V. P. (1986). The geology and geomorphology of the Venus surface as revealed by the radar images obtained by Veneras 15 and 16. Journal of Geophysical Research: Solid Earth, 91(B4), 378-398.

Basilevsky, A. T., \& Head, J. W. (2002). Venus: Timing and rates of geologic activity. Geology, 30(11), 1015-1018.

Basilevsky, A. T., \& Head III, J. W. (1998). The geologic history of Venus: A stratigraphic view. Journal of Geophysical Research: Planets, 103(E4), 8531-8544.

Basilevsky, A. T., \& McGill, G. E. (2007). Surface evolution of Venus. Geophysical Monograph-American Geophysical Union, 176, 23.

Bethell, E., Ernst, R.E., Samson, C., Buchan, K.L. (2016). Circumferential Graben-Fissure Systems of Venusian Coronae as Possible Analogues of Giant Circumferential Dyke Swarms on Earth. Lunar and Planetary Science XXXXVII (2016). Abstract 1471.

Bethell, E. M., Ernst, R. E., \& Samson, C. (2019). Geology of the Alpha Regio (V-32) Quadrangle, Venus. Journal of Maps, 15(2), 474-486.

Bethell, E. M., Ernst, R. E., \& Samson, C. (2020). Morphometry of Wrinkle Ridges, Southern Eistla Regio, Venus. Lunar and Planetary Science LI (2020). Abstract 1278.

Bindschadler, D. L., DeCharon, A., Beratan, K. K., Smrekar, S. E., \& Head, J. W. (1992). Magellan observations of Alpha Regio: Implications for formation of complex ridged terrains on Venus. Journal of Geophysical Research: Planets, 97(E8), 13563-13577.

Bindschadler, D. L., \& Head, J. W. (1989). Characterization of Venera 15/16 geologic units 
from Pioneer Venus reflectivity and roughness data. Icarus, 77(1), 3-20.

Bindschadler, D. L., \& Head, J. W. (1991). Tessera terrain, Venus: Characterization and models for origin and evolution. Journal of Geophysical Research: Solid Earth, 96(B4), 58895907.

Bindschadler, D. L., Schubert, G., \& Kaula, W. M. (1992). Coldspots and hotspots: Global tectonics and mantle dynamics of Venus. Journal of Geophysical Research: Planets, 97(E8), 13495-13532.

Bleamaster, L. F., \& Hansen, V. L. (2005). Geologic map of the Ovda Regio quadrangle (V-35), Venus. Geologic Investigations Series, I-2808

Bray, V. J., Bussey, D. B. J., Ghail, R. C., Jones, A. P., \& Pickering, K. T. (2007). Meander geometry of Venusian canali: Constraints on flow regime and formation time. Journal of Geophysical Research: Planets, 112(E4), 3-6.

Bridge, J., \& Demicco, R. (2008). Earth surface processes, landforms and sediment deposits. Earth Surface Processes and Landforms, 45(1), 75-95.

Buchan, K.L., Ernst, R.E. (2016). Giant Circumferential Dyke Swarms on Earth as Possible Analogues of Coronae on Venus. Lunar and Planetary Science XXXXVII (2016). Abstract 1183.

Byrnes, J. M., \& Crown, D. A. (2002). Morphology, stratigraphy, and surface roughness properties of Venusian lava flow fields. Journal of Geophysical Research: Planets, 107(E10), 9-1.

Byrne, P. K., Ghail, R., Gilmore, M. S., Sengor, A. C., Klimczak, C., Solomon, S. C., ... \& Ernst, R. E. (2019). Geological Significance of Preserved Interior Structures in Venus Tessera Units. In AGU Fall Meeting 2019. AGU. 
Byrne, P. K., Ghail, R., Gilmore, M. S., Sengor, A. C., Klimczak, C., Solomon, S. C., ... \& Ernst, R. E. (2020). Some Venus Tesserae Feature Layered, Folded and Eroded Rocks. Lunar and Planetary Science LI (2020). Abstract 2514.

Campbell, I. H., \& Taylor, S. R. (1983). No water, no granites-No oceans, no continents. Geophysical Research Letters, 10(11), 1061-1064.

Chaisson, E., \& McMillan, S. (2010). Astronomy Today, Vol. 1-The Solar System. Astronomy Today, 228-259.

Craddock, R. A. (2012). Aeolian processes on the terrestrial planets: Recent observations and future focus. Progress in Physical Geography, 36(1), 110-124.

Davey, S.C., Ernst, R.E., Samson, C., Grosfils, E.B. (2013). Hierarchical Clustering of Pit Crater Chains on Venus. Canadian Journal of Earth Science 50, 109-126.

Davey, S. (2012). Mapping radiating graben-fissure systems and pit crater chains on Venus (MSc thesis, Carleton University, Ottawa Canada).

Donahue, T. M., \& Russell, C. T. (1997). The Venus atmosphere and ionosphere and their interaction with the solar wind: An overview. In Venus II: Geology, Geophysics, Atmosphere, and Solar Wind Environment (p. 3-8).

Dong, R., \& Dong, Z. (2018). Aesthetic evaluation of yardang landforms landscape: the Dunhuang Yardang National Geo-park example.Sciences in Cold and Arid Regions, 7(3), 265-271.

Ernst, R. E., Buchan, K. L., \& Desnoyers, D. W. (2007). Plumes and plume clusters on Earth and Venus:evidence from large igneous provinces (LIPS). In Superplumes: Beyond Plate Tectonics (pp. 537-562). Springer, Dordrecht. 
Ernst, R.E., Buchan, K.L. (1995). Giant Radiating Dyke Swarms: Their Use in Identifying PreMesozoic Large Igneous Provinces and Mantle Plumes. AGU Geophysical Monograph 100, 297-333.

Ernst, R.E., Buchan, K.L. 1997b. Layered Mafic Intrusions: A Model for Their Feeder Systems and Relationship with Giant Dyke Swarms and Mantle Plume Centers. South African Journal of Geology 100, 319-334.

Ernst, R.E., Buchan, K.L. 2001. The Use of Mafic Dyke Swarms in Identifying and Locating Mantle Plumes. Geological Society of America, Special Paper 352, pp. 247-265.

Ernst, R.E. \& Buchan, K.L. (eds), Mantle Plumes: Their Identification Through Time. Geological Society of America, Special Paper 352, pp. 483-575.

Ernst, R.E., Buchan, K.L., Palmer, H.C. 1995a. Giant Dyke Swarms: Characteristics, Distribution and Geotectonic Applications. In Baer, G. \& Heimmann, A. (eds), Physics and Chemistry of Dykes. Rotterdam: Balkema, pp. 3-21.

Ernst, R.E., Desnoyers, D.W. 2004. Lessons from Venus for Understanding Mantle Plumes on Earth. Physics of the Earth and Planetary Interiors 146, 195-229.

Ernst, R.E., Desnoyers, D.W., Head, J.W., Grosfils, E.B. 2003. Graben-Fissure Systems in Guinevere Planitia and Beta Regio (264o-312oE, 24o-60oN), Venus, and Implications for Regional Stratigraphy and Mantle Plumes. Icarus 164, 282-316.

Ernst, R.E., Grosfils, E.B., Mege, D. 2001. Giant Dyke Swarms: Earth, Venus, Mars. Annual Review of Earth and Planetary Sciences 29, 489-534.

Ernst, R.E., Head, J.W., Parfitt, E., Grosfils, E.B., Wilson, L. 1995b. Giant Radiating Dyke Swarms on Earth and Venus. Earth Science Reviews 39, 1-58. 
Ernst, R. E., Samson, C., Kuiper, Y. D., \& Khawja, S. (2019). Geological Testing of Climate Change Models on Venus. Lunar and Planetary Science Conference LI (2019). Abstract 2132.

Ernst, R. E., Samson, C., E. Bethell., \& Khawja, S. (2020). Geological Constraints on the Timing of the Extreme Warming Climate Transition on Venus. Lunar and Planetary Science Conference (2020). Abstract 2193.

Ford, P. G., \& Pettengill, G. H. (1992). Venus topography and kilometer-scale slopes. Journal of Geophysical Research: Planets, 97(E8), 13103-13114.

Ghent, R. R., \& Hansen, V. L. (1997). Structural analysis of central and eastern Ovda Regio, Venus. In Lunar and Planetary Science Conference XXVIII (1997). Abstract 1301.

Gilmore, M. S., \& Head, J. W. (2018). Morphology and deformational history of Tellus Regio, Venus: Evidence for assembly and collision. Planetary and Space Science, 154, 5-20.

Gilmore, M. S., Ivanov, M. A., Head III, J. W., \& Basilevsky, A. T. (1997). Duration of tessera deformation on Venus. Journal of Geophysical Research: Planets, 102(E6), 1335713368.

Goudie, A. S. (2007). Mega-yardangs: A global analysis. Geography Compass, 1(1), 65-81.

Graff, J. R. (2016). A History of Tectono-Magmatism along the Parga Chasma Rift System on Venus (MSc thesis, Carleton University).

Greeley, R., Arvidson, R. E., Elachi, C., Geringer, M. A., Plaut, J. J., Saunders, R. S., ... \& Weitz, C. M. (1992). Aeolian features on Venus: preliminary Magellan results. Journal of Geophysical Research: Planets, 97(E8), 13319-13345. 
Grosfils, E.B., Ernst, R.E., Galgana, G.A. (2014). Radiating Lineament System. In: Hargitai, H., \& A. Kereszturi. Encyclopedia of Planetary Landforms, pp 1-10.

Grosfils, E.B., Head, J.W. (1994) The Global Distribution of Giant Radiating Dike Swarms on Venus: Implications for the Global Stress State. Geophysical Research Letters 21, 701704.

Hanmer, S. (2020). Tessera terrain ribbon fabrics on Venus reviewed: Could they be dyke swarms? Earth-Science Reviews, 103077.

Hansen, V. L. (2006). Geologic constraints on crustal plateau surface histories, Venus: The lava pond and bolide impact hypotheses. Journal of Geophysical Research: Planets, 111(E11).

Hansen, V. L., Phillips, R. J., Willis, J. J., \& Ghent, R. R. (2000). Structures in tessera terrain, Venus: Issues and answers. Journal of Geophysical Research: Planets, 105(E2), 41354152.

Hansen, V. L., \& Willis, J. A. (1996). Structural analysis of a sampling of tesserae: Implications for Venus geodynamics. Icarus, 123(2), 296-312.

Hansen, V. L., \& Willis, J. J. (1998). Ribbon terrain formation, southwestern Fortuna Tessera, Venus: Implications for lithosphere evolution. Icarus, 132(2), 321-343.

Herrick, R. R., Stahlke, D. L., \& Sharpton, V. L. (2012). Fine-scale Venusian topography from Magellan stereo data. Eos, Transactions American Geophysical Union, 93(12), 125-126.

Hoffman, J. H., Hodges, R. R., Donahue, T. M., \& McElroy, M. B. (1980). Composition of the Venus lower atmosphere from the Pioneer Venus mass spectrometer. Journal of Geophysical Research: Space Physics, 85(A13), 7882-7890. 
Ivanov, M. A., \& Basilevsky, A. T. (1993). Density and morphology of impact craters on tessera terrain, Venus. Geophysical Research Letters, 20(23), 2579-2582.

Ivanov, M. A., \& Head, J. W. (2011). Global geological map of Venus. Planetary and Space Science, 59(13), 1559-1600.

Ivanov, M. A., \& Head, J. W. (1996). Tessera terrain in Ovda Regio, Venus: Preliminary results of a geologic mapping traverse. Lunar and Planetary Science Conference XXVII (1996). pp 591.

Ivanov, M. A., \& Head, J. W. (1996). Tessera terrain on Venus: A survey of the global distribution, characteristics, and relation to surrounding units from Magellan data. Journal of Geophysical Research: Planets, 101(E6), 14861-14908.

Ivanov, B. A., \& Melosh, H. J. (2003). Impacts do not initiate volcanic eruptions: Eruptions close to the crater. Geology, 31(10), 869-872.

Kane, S. R., Arney, G., Crisp, D., Domagal-Goldman, S., Glaze, L. S., Goldblatt, C., ... \& Way, M. J. (2019). Venus as a laboratory for exoplanetary science. Journal of Geophysical Research: Planets, 124(8), 2015-2028.

Khawja, S., Ernst, R. E., Kuiper, Y. D., \& Samson, C. (2019). Structural Analysis of Salus Tessera, Venus: Interpreting Surface Lineament Sets Using Topographic Profiles. Lunar and Planetary Science Conference L (2019). Abstract 1967.

Khawja, S., Ernst, R.E., Samson, C., Byrne, \& P.K., Ghail, R.C. (2020 March). Erosional Features on Tessera Terrains, Venus. Lunar and Planetary Science Conference LI (2020). Abstract 1161.

Kirschvink, J. L. (1980). The least-squares line and plane and the analysis of palaeomagnetic data. Geophysical Journal International, 62(3), 699-718. 
MacLellan, L.M., \& Ernst, R.E. (2020 March). Volcanic History of Derceto-Kallistos-Ubastet Lip, Lada Terra, Venus. Lunar and Planetary Science Conference LI (2020). Abstract 1105.

Magee, K. P., \& Head, J. W. (2001). Large flow fields on Venus: Implications for plumes, rift associations, and resurfacing. In: Ernst, R.E., Buchan, K.L. (eds.) Mantle plumes: their identification through time, Geological Society of America Special Paper 352, 81-93.

Oshigami, S., Namiki, N., \& Komatsu, G. (2009). Depth profiles of Venusian sinuous rilles and valley networks. Icarus, 199(2), 250-263.

Pritchard, M. E., Hansen, V. L., \& Willis, J. J. (1997). Structural evolution of western Fortuna Tessera, Venus. Geophysical Research Letters, 24(18), 2339-2342.

Romeo, I., \& Turcotte, D. L. (2008). Pulsating continents on Venus: An explanation for crustal plateaus and tessera terrains. Earth and Planetary Science Letters, 276(1-2), 85-97.

Saunders, R.S., Pettengill, G.H. (1991). Magellan Mission summary. Science 252, 247-249.

Saunders, R. S., Spear, A. J., Allin, P. C., Austin, R. S., Berman, A. L., Chandlee, R. C., ... \& Gunn, J. M. (1992). Magellan mission summary. Journal of Geophysical Research: Planets, 97(E8), 13067-13090.

Saunders, R.S., Spear, A.J., Allin, P.C., Austin, R.S., Berman, A.L., Chandlee, R.C., Clark, J., DeCharron, A.V., De Jong, E.M., Griffifith, D.G., Gunn, J.M., Hensley, S., Johnson, W.T.K., Kirby, C.E., Leung, K.S., Lyons, D.T., Michaels, G.A., Miller, J., Morris, R.B., Piereson, R.G., Scott, J.F., Shaffer, S.J., Slonski, J.P., Stofan, E.R., Thompson, T.W., and Wall, S.D. 1992. Magellan Mission Summary. Journal of Geophysical Research 97, 13067-13090.

Senske, D. A. (1999). Geology of the Tellus Tessera quadrangle (V-10), Venus. 
Lunar and Planetary Science Conference XXX (1999). Abstract 1668.

Smrekar, S. E., Stofan, E. R., Mueller, N., Treiman, A., Elkins-Tanton, L., Helbert, J., ... \& Drossart, P. (2010). Recent hotspot volcanism on Venus from VIRTIS emissivity data. Science, 328(5978), 605-608.

Solomon, S. C., Head, J. W., Kaula, W. M., McKenzie, D., Parsons, B., Phillips, R. J., ... \& Talwani, M. (1991). Venus tectonics: Initial analysis from Magellan. Science, 252(5003), 297312.

Solomon, S. C., Smrekar, S. E., Bindschadler, D. L., Grimm, R. E., Kaula, W. M., McGill, G. E., ... \& Stofan, E. R. (1992). Venus tectonics: An overview of Magellan observations. Journal of Geophysical Research: Planets, 97(E8), 13199-13255.

Solomon, S. C. (1993). The geophysics of Venus. Physics Today, 46, 48-55.

Sukhanov, A. L. (1992). Tesserae are not Alterted Plains, Venus. Lunar and Planetary Science Conference XXII (1992). pp 1357.

Turcotte, D. L. (1993). An episodic hypothesis for Venusian tectonics. Journal of Geophysical Research: Planets, 98(E9), 17061-17068.

Way, M. J., Del Genio, A. D., Kiang, N. Y., Sohl, L. E., Grinspoon, D. H., Aleinov, I., ... \& Clune, T. (2016). Was Venus the first habitable world of our solar system? Geophysical research letters, 43(16), 8376-8383.

Whitten, J. L., \& Campbell, B. A. (2016). Recent volcanic resurfacing of Venusian craters. Geology, 44(7), 519-522.

Young, C. (1990). The Magellan Venus explorer's guide. National Aeronautics and Space Administration. 
Zimbelman, J. R. (2003). Flow field stratigraphy surrounding Sekmet Mons Volcano, Kawelu Planitia, Venus. Journal of Geophysical Research: Planets, 108(E5). 